\title{
Fusion Breeding for Mid-Century Sustainable Power
}

\author{
Wallace Manheimer
}

Published online: 25 March 2014

(C) The Author(s) 2014. This article is published with open access at Springerlink.com

\begin{abstract}
This article is an editorial, which makes the case that fusion breeding (that is using fusion neutrons to breed nuclear fuel for use in conventional nuclear reactors) is the best objective for the fusion program. To make the case, it reviews a great deal of plasma physics and fusion data. Fusion breeding could potentially play a key role in delivering large-scale sustainable carbon-free commercial power by mid-century. There is almost no chance that pure fusion can do that. The leading magnetic fusion concept, the tokamak, is subject to well-known constraints, which we have called conservative design rules, and review in this paper. These constraints will very likely prevent tokamaks from ever delivering economical pure fusion. Inertial fusion, in pure fusion mode, may ultimately be able to deliver commercial power, but the failure to date of the leading inertial fusion experiment, the National Ignition Campaign, shows that there are still large gaps in our understanding of laser fusion. Fusion breeding, based on either magnetic fusion or inertial fusion, greatly relaxes the requirements on the fusion reactor. It is also a much better fit to today's and tomorrow's nuclear infrastructure than is its competitor, fission breeding. This article also shows that the proposed fusion and fission infrastructure, 'The Energy Park', reviewed here, is sustainable, economically and environmentally sound, and poses little or no proliferation risk.
\end{abstract}

Keywords Fusion breeding - Sustainable power . Sustainable midcentury power $\cdot$ Hybrid fusion

Wallace Manheimer-Retired from the Naval Research Laboratory.

W. Manheimer $(\bowtie)$

Allendale, NJ, USA

e-mail: wallymanheimer@yahoo.com

\section{Introduction}

The fusion program, both short term and long term, is in trouble, certainly in the United States, and likely worldwide. In addition to large cost overruns and failures to meet milestones, surely another reason is that pure fusion has almost no chance of meeting energy requirements on a time scale that anyone alive today can relate to. Hence the assertion of this article is that fusion breeding of conventional nuclear fuel is a likely way out of fusion's current and future difficulties. Fusion breeding substantially reduces the requirements on the fusion reactor. It significantly reduces the necessary $\mathrm{Q}$ (fusion power divided by input power), wall loading, and availability fraction. The capital cost of a reactor, estimated based on ITER's capital cost, is affordable for fusion breeding, but definitely is not for pure fusion. It is likely that fusion breeding can produce fuel at a reasonable cost by mid century. The entire fusion and fission infrastructure would be sustainable, economical, environmentally sound, and have little or no proliferation risk. This article's mission then, is to hopefully convince a much larger portion of the fusion establishment to make this case. At the very least it hopes to broaden the discussion in the fusion community from where we are now, where one prestigious review committee after another insists that every existing project is absolutely vital, nothing can be changed; except give us more $\$ \$ \$$. The inevitable result of this process is that one fusion project after another gets knocked off.

The choice of fusion breeding versus pure fusion does not mean an immediate departure from the current course, but perhaps a 30 degree course correction. Many, but not all initial tasks are common to both options. However even with a 30 degree correction, after some distance traveled, the two paths diverge and are quite far apart. What is 
needed immediately then is a change in psychology in the fusion effort, that is a realization that breeding is a different, perfectly acceptable, and perhaps even a better option for fusion; and certainly one that is more achievable.

There is a natural symbiosis between fission and fusion. Fusion is neutron rich and energy poor; fission is energy rich and neutron poor. A fusion reaction, which produces about $20 \mathrm{MeV}$, creates 2-3 neutrons after neutron multiplication. The fission reaction produces the same 2-3 neutrons, but $200 \mathrm{MeV}$. Thus, for equivalent output power, fusion generates ten times as many neutrons as fission. A fusion reactor can be a very prolific fuel producer for fission reactor, which would be the primary energy producer.

Fusion proponents, for the most part, see fusion as an inherently safe energy source with minimal issues of hazardous waste and an inexhaustible fuel supply. They would prefer not to tie their fortunes to fission, which might not even want them, and which they see as having issues of safety, proliferation, and long-term radioactive waste. But they should consider realities. Fusion breeding is at least an order of magnitude easier to pull off than pure fusion power. It should be possible, whereas commercial application of pure fusion may turn out not to be. Even in the best of circumstances, commercial fusion breeding should be available quite a few decades earlier than commercial pure fusion. Thus it could serve as an intermediate objective, of genuine economic value, on the path to pure fusion.

With the recent disaster at Fukushima, and the sudden advent an era of inexpensive natural gas from hydraulic fracturing, that is, fracking, this hardly seems to be the optimum time to argue for an energy source that is largely nuclear. However this article takes a longer view.

An "inconvenient truth" is that the world may well have a climate problem by mid century, forcing it to move away from carbon-based fossil fuels even if they are not on a rapid path to depletion, which they may well be. But another "inconvenient truth" is that advanced economies require energy, and lots of it. And a third "inconvenient truth" is that the world is very unequal today, but the lessdeveloped nations are pushing very hard for economic equality. It will be apparent by mid-century that the world has a very big long-term energy problem. Today $20 \%$ or so of the world's population uses the lion's share of the 14 terawatts (TW) of power the world generates. By midcentury this will no longer be acceptable; everybody will demand the better life style abundant power makes possible. In a much cited paper, Hoffert et al. [1] argue that the world will need an additional 10-30 TW of carbon-free energy by mid-century.

And where will the world get this carbon-free energy? This author is convinced [2] that solar energy (solar thermal, solar photo voltaic, wind and biofuel) will contribute only a small fraction of this energy. As an example consider wind. First of all, much information we read is misleading. This author has seen mostly the 'nameplate power' quoted. This is the power the windmill of wind farm produces when the wind blows at exactly the right speed and direction. The average power, or the actual power is considerably less. According to the Wikipedia article on wind power (http://en.wikipedia.org/wiki/Wind_ power), the actual wind power produced in 2011 was about 50 gigawatts $(\mathrm{GW})$, about $0.36 \%$ of the total world power of $14 \mathrm{TW}$. In other words, after more than 20 years of heavily subsidized development, if one takes the percentage of world power produced by wind, and rounds it off the nearest whole number, that percentage is zero.

In the absence of carbon free power sources, right now the world gets its energy from coal. Coal is overtaking oil as the largest source of power, its use is rapidly accelerating [3]. Rapidly developing countries like China, Indonesia, Turkey... are greatly increasing their use of coal. But if fossil fuel use, and especially coal, has to be reduced because of fears of climate change and/or depletion of a finite resource; and if wind, solar and biofuel cannot do it; what else is there? If not nuclear, then what?

Fission and fusion are the only carbon-free technologies that could power a world with 10 billion people. Fusion has many potential advantages as an energy source, but even its most optimistic proponents recognize that commercial fusion energy will not be ready any time near mid century. For nearly half a century, fusion's advocates have been planning for a DEMO (a precursor to a commercial reactor) 35 years from $\mathrm{t}=0$, and who knows when $\mathrm{t}=0$ will be? [4].

Fission, on the other hand, is a technology that works well now, but the supply of fissile ${ }^{235} \mathrm{U}$ is limited. Fission can be a long-term, sustainable solution only if breeders are used to convert ${ }^{238} \mathrm{U}$ or thorium into fissile fuel. There are two options for breeders: fast-neutron fission reactors or fusion reactors. Fission breeding has a head start, but fusion breeding, advocated by this author for 15 years now is by far the more attractive option [4-11]. Fusion breeding is a much easier technology than pure fusion as an energy source; it could be commercialized by mid-century. Furthermore, fusion breeding could naturally serve as an economical bridge to pure fusion in the much more distant future.

Then it is also worth noting that both Andrei Sakharov [12] and Hans Bethe [13] advocated fusion breeding instead of pure fusion. These are two physicists we ignore at our peril.

We will see that for pure fusion to become economically feasible, either ITER or NIF would have to be greatly improved. Yet all experience shows that once systems get to be that size, progress comes with glacial lethargy, if comes at all. For instance it was 20 years from when ITER 
was proposed until it was approved, then another 15 years until first plasma, and another 7 (if all goes well) until DT experiments can even begin. This 42 year period, just to get to the starting gate, is longer than the total career of a typical physicist.

Furthermore, as we will also shortly see, pure fusion may well be out of reach for tokamaks. However an ITER or NIF scale system is more than adequate for fusion breeding. We will see the Q that ITER or NIF hopes to achieve is not nearly sufficient for pure fusion but definitely fine is for breeding. The first wall of a pure fusion reactor would have to be able to withstand a neutron flux of at least $4 \mathrm{MW} / \mathrm{m}^{2}$; but as we will see, a fusion breeder is fine with ITER scale wall loadings of one, or perhaps even half a megawatt per square meter. If the fusion reactor principally breeds, fuel and is only secondarily a power source, its availability fraction is not such a critical consideration either.

One obvious question then is why develop fusion breeding, decades in the future; when we are not developing fission breeding today? One answer is that there is no immediate need for either fission or fusion breeding. For the next few decades, fissile fuel is readily available. However the need for one or both will be pressing by mid century [1]. A key advantage of fusion breeding, is that it is about an order of magnitude more prolific than fission breeding. That is one fusion breeder can fuel about five light water reactors (LWR's) of equal power, whereas it takes two fission breeders, for instance two integral fast reactors (IFR) at maximum breeding rate to fuel a single LWR of equal power [14-18], (http://en.wikipedia.org/ wiki/Integral_fast_reactor). Clearly fusion breeding fits in well with today's (and very likely tomorrow's) nuclear infrastructure; fission breeding does not. In other words, in a fission breeder economy, at least $2 / 3$ of the reactors would have to be breeders and this will represent a staggering cost. In a fusion breeder economy, all of the LWR's, here and in the future, would remain in place.

Thus fusion breeding does not have to compete with LWR's, a competition likely unwinnable if fuel supply for LWR's were no consideration. It only has to compete with fission breeders, a competition it might well win. But more realistically, in a competition between fission and fusion breeding, there will likely be room in the midcentury economy for both, at least if fusion breeding makes a real effort to compete.

A fusion breeder economy does envision a vital role for fast neutron fission reactors. A single IFR (which in fact can run as either a breeder or burner), can burn any actinide. If run as a perfectly efficient burner, it can burn the actinide wastes of about 5 LWR's (an LWR each year releases about $1 / 5$ of the fuel it starts with in the form of actinide by products) [19]. Thus we can envision a sustainable, mid century, fusion breeding based energy architecture, where a single fusion breeder fuels 5 LWR's, the nuclear reactor of choice up to now, and a single IFR burns up the actinide waste of these 5 LWR's. The only waste products would be those fission decay products (cesium 137, strontium 90, etc.) which have no commercial value, but which have half lives of about 30 years. These could be stored for 300-600 years, a time human society can reasonably plan for, not the half million or so years it would take for, for instance ${ }^{239} \mathrm{Pu}$ (half life 24,000 years), to decay away.

There is some dispute about the amount of uranium fuel available. Hoffert et al. [1], measuring it in terawatt years, estimates 60-300 TW years of uranium fuel is available. He mentioned that if the lowest estimate is correct, and 10 TW are needed (right now the world uses about $300 \mathrm{GWe}$, or about 1 TWth of nuclear power), there is only enough fuel for 6 years, hardly enough to justify creating a large, multi terawatt infrastructure. However other sources estimate that the available fuel is much greater [20]. This paper certainly cannot sort out these conflicting estimates. But one thing is indisputable. No matter how much nuclear fuel fission advocates think they have, they must admit that their supply of fissile nuclear fuel is $<1 \%$ of the uranium resource, and $0 \%$ of the thorium. Fusion breeding makes about $50-100 \%$ of each available. This author does not believe the world is so well endowed with energy resources that we can afford to discard more than $99 \%$ of them. To get an idea of the size of this resource, thermal nuclear reactors have been delivering about $300 \mathrm{GWe}$ for about 40 years. This means that in depleted uranium alone, there is sufficient fuel for 3 TWe for 200-400 years! But as we will see, a much better option is to use thorium as a fuel, and there is three times as much thorium as uranium. Nuclear fuel, for all practical purposes, is inexhaustible in the same sense as wind or solar [21].

Hence a conservative approach is to assume the worst as regards nuclear fuel supply and support a relatively low cost, economical way of enhancing it by about two orders of magnitude, i.e. fusion breeding. Supporting fusion breeding will not produce appreciable fuel until mid century at best; and by then there could well be a crying need for it.

Then to reiterate our basic case, this article makes the case that (1) The optimum strategy is not pure fusion, i.e. using the neutron's $14 \mathrm{MeV}$ kinetic energy to boil water; but fusion breeding, i.e. using what, for want of a better term, we call the neutron's potential energy, to breed 10 times more fuel, and its kinetic energy to boil water. This is especially true if one adopts the tokamak approach, because conservative design rules, which we will discuss shortly, and which have limited tokamak operation for half a century appear to forbid pure fusion, but allow fusion 
breeding. Of all the hybrid fusion options, the most sensible is breeding. Recently a summary of many different possible types of many different fusion fission hybrids has appeared [20]. While not explicitly concluding that breeding is the best option, it does seem to point toward it. Our own book chapter summarizing hybrids does explicitly recommend breeding among the options [11]. A valuable resource for anyone interested in fusion breeding or other forms of hybrid fusion is a web site set up by Ralph Moir (www.ralphmoir.com). (2) The fusion configurations should continue along the paths being blazed by ITER and NIF, and not divert scarce resources to other approaches. (3) The mid century energy infrastructure will necessarily have a large nuclear component. Fission now supplies about $300 \mathrm{GWe}$, or about $13 \%$ of the $2.5 \mathrm{TW}$ the world generates. There are about 400 fission power plants now, and about 70 more are in various stages of construction or planning. There is no reason to think that nuclear power generation cannot be considerably increased. By mid century, fusion breeders could be supplying their fuel and fast neutron reactors could be burning the actinide wastes.

Recently Ralph Moir, along with this author has contributed a chapter on hybrid fusion to a textbook [11]. This chapter concentrated on the nuclear aspects, while not ignoring the plasma. By contrast, this article concentrates mostly on the plasma aspects, while not ignoring the nuclear, and may be regarded as a companion to the book chapter.

Now let's get to fusion's difficulties. Consider first ITER [22]. When it was approved in 2005, the construction cost was estimated at about 5 billion euros, with a start date of 2106. In 4 years, the cost has tripled to 16 billion euros, and the start date to 2019 [23]. Some estimates have put the cost of ITER even higher. Here is Senator Diane Feinstein [24], chair of the subcommittee on Energy and Water Development of the Senate on the rapidly increasing cost of ITER:

"We provide no funding for ITER until the department (of energy) provides this committee with a baseline cost, schedule and scope."

Now consider NIF, another multibillion dollar machine. It was supposed to achieve ignition in FY 2012. As of this writing (fall 2013 and winter, 2013-2014) it has not only failed, but has failed in spectacular fashion. While it now routinely generates laser shots of well over a megajoule, the best gains they have achieved are still $<10^{-2}$, more than three orders of magnitude below original predictions. The Lawrence Livermore Laboratory has recently published a paper on where NIF is now, pointing out that on their best shot, they achieved about $10^{15}$ neutrons, about $3 \mathrm{~kJ}$ [25]. Recent efforts have done somewhat better [26].

Here is the House Appropriations Committee [27] on the failure of NIF to achieve ignition:
"As the first ignition campaign comes to a close in fiscal year 2012, it is a distinct possibility that the NNSA will not achieve ignition during these initial experiments. While achieving ignition was never scientifically assured, the considerable costs will not have been warranted if the only role of the National Ignition Facility (NIF) is that of an expensive platform for routine high energy density physics experiments."

Thus fusion's two gigantic flagships, ITER and NIF appear to be taking in water. However NIF is, and ITER unquestionably will be unique, priceless, world class resources which this author is confident will ultimately make very major contributions to fusion. But fusion has long term problems, which are even more serious. While these short and long term problems are not obviously related, a more credible long term strategy will help in the short term as well. The fact that fusion breeding fits in very well with todays and tomorrows likely nuclear infrastructure so that it could be introduced gradually and seamlessly enhances the case further.

To illustrate ITER's long term problems, consider its goal as stated on the ITER web site (www.iter.org):

"The Q in the formula on the right symbolizes the ratio of fusion power to input power. $\mathrm{Q} \geq 10$ represents the scientific goal of the ITER project: to deliver ten times the power it consumes. From $50 \mathrm{MW}$ (megawatts) of input power, the ITER machine is designed to produce $500 \mathrm{MW}$ of fusion power-the first of all fusion experiments to produce net energy."

So how close would we be to a reactor? The $500 \mathrm{MW}$ of fusion thermal power typically has an efficiency of conversion to electricity power of about $1 / 3$, so it generates about $170 \mathrm{MWe}$. However the driver, beams or radiation need about $50 \mathrm{MW}$. But accelerators and radiation sources are not $100 \%$ efficient either. Again, one third is a more reasonable estimate, so the drivers would need $150 \mathrm{MW}$ of the electric power produced, leaving all of $20 \mathrm{MWe}$ for the grid. Clearly ITER would have to be greatly improved before it could begin to be regarded as an economical power source.

But what about the fact that ITER could be a burning plasma so much less input power is needed. Again, here is the ITER web site:

"The ITER Tokamak will rely on three sources of external heating that work in concert to provide the input heating power of $50 \mathrm{MW}$ required to bring the plasma to the temperature necessary for fusion. These are neutral beam injection and two sources of high-frequency electromagnetic waves.

Ultimately, researchers hope to achieve a "burning plasma"-one in which the energy of the helium nuclei produced by the fusion reaction is enough to maintain the temperature of the plasma. The external heating can then 
be strongly reduced or switched off altogether. A burning plasma in which at least 50 percent of the energy needed to drive the fusion reaction is generated internally is an essential step to reaching the goal of fusion power generation."

Hence a burning plasma does not seem to be anything like one of ITER's initial goals, but taking their figure of a reduction of input power by $50 \%$, this means that only $25 \mathrm{MW}$ of external power is needed, leaving perhaps 100 MWe for the grid; small power for a \$20B facility. In this paper the original Large ITER is also considered [28]. Roughly it produces about 3 times the power, still with $\mathrm{Q}=10$. At the time the switch was made, the cost of Large ITER was estimated to be about a factor of 2 larger than the cost of ITER. However the cost is very much a moving target; who knows what Large ITER would cost, were estimated today. Here we still do consider mostly a Large ITER based breeder.

In any case, the performance of ITER would have to be upgraded by a very great amount before it could be considered as a potential economical power source. But this could be particularly difficult for ITER, even if it requires no input power. The reason is that tokamak performance has always been constrained by what this author has called 'conservative design rules', to be discussed in the next section. These rules indicate that a pure fusion tokamak could be extremely difficult, whereas a tokamak breeder can operate well within these constraints.

Now let's consider NIF another multibillion dollar machine. Let's stipulate a gain of 100 from a megajoule laser pulse (current best gains $10^{-3}-10^{-2}$ ), a laser wall plug efficiency of $3 \%$ (currently $<1 \%$ ) pulse rate of $15 \mathrm{~Hz}$ (currently about 1-2 shots per day) generating the same $1.5 \mathrm{GWth}$, or $500 \mathrm{MWe}$, just as one would estimate for Large ITER. However each laser pulse needs $30 \mathrm{MJ}$ of electricity to drive it, leaving all of 50 megawatts for the grid.

Hence even stipulating the maximum success for either ITER or NIF, we are still very, very far from economical fusion. This is the serious long term problem that fusion has. After all, if neither ITER nor NIF brings us very close to fusion, what are our sponsors paying for; another half century, or century of effort starting with their success? The great advantage of fusion breeding is that ITER and NIF sized devices could be ends in themselves rather than stepping stones to who knows what DEMO, built who knows how many decades later? Using breeding the author believes fusion could very likely make a major impact on the energy systems in our grand children's prime (mine are 9, 12, and 14); without, it maybe their grand children's.

Yet what are the alternatives to tokamaks and lasers? Each of these technologies were developed through a four to five decade international effort, costing billions to get to where they are today. Many other concepts have their proponents who assure us that they can achieve fusion very quickly if only we fund them at the required level. For instance Robert Burke claims that we could get there very quickly via heavy ion beam fusion [29]. In the past, the proponents of these concepts have sought government funding, but recently they have been seeking venture capital funding. One such enterprise, Fusion Power Corp. of Sacramento CA, promises commercial power in 10 years [30] via heavy ion beam inertial fusion. But the high-current ion accelerators and/or storage rings required for heavy ion fusion are at this point merely concepts that have been studied theoretically for over 30 years at Lawrence Berkeley National Laboratory (LBNL) and other labs, but never built. Their feasibility has not been demonstrated, and they would cost billions to build. Is that kind of money available in the private sector for a speculative concept? If so, we can only wish them the best of luck. General Fusion Company in Vancouver Canada, funded by Jeff Bezos of Amazon at $\$ 30 \mathrm{M}$, puts even that time scale to shame. Using magnetized target fusion [31], a concept that was studied over the past 30 years at the Naval Research Laboratory (NRL) and the Los Alamos National Laboratory (LANL), they promise break-even by 2014 and a commercial reactor by 2020 .

Maybe; and of course maybe a genius will invent a commercial fusion reactor in his or her garage.

But more realistically, any other concept, starting from where it is now will probably take the same time and effort to get to where tokamaks and lasers are today. And this of course assumes that these other concepts are even as good, despite the fact that they have already been rejected in favor of tokamaks and lasers. Also without getting very far into the politics, is there really any chance that congress would appropriate many billions more for say a stellarator if ITER fails, or a heavy ion accelerator if NIF continues to fail? What with fracking and cheap gas now, do our sponsors really have the stomach for this? Who knows, in the dim distant future, stellarators or heavy ion accelerators may prove to be superior to tokamaks or lasers. But realistically, the only way we will learn this is if they are follow on projects to successes at ITER and NIF.

To this author's mind the best hope for fusion is to get an ITER or NIF like system to be an economical power producer. The best way to achieve this is to use fusion neutrons to breed fuel for conventional nuclear reactors, likely, but not necessarily light water reactors (LWR's). The more than order of magnitude increase in $Q$ in the breeding blanket could provide just the boost needed to accomplish this. Let us be clear here, that by an order of magnitude increase in $\mathrm{Q}$, we included the power produced directly by the fusion reactor plus the power of the fuel, 
which is produced by the fusion reactor, but is burned elsewhere.

But of course this results in a difficult dilemma. Fission people mostly (but not unanimously) think they have enough fuel, and are fighting for their own survival on other fronts. For instance Germany plans to mothball its 17 nuclear reactors, and hence is going through something of an energy crisis now. Also fusion people do not want to get their hand dirty. This paper attempts to take on and answer these arguments.

Section II reviews magnetic fusion. It concentrates on the tokamak in some detail. It discusses other options in much less detail, and mostly makes the case that none of these are nearly ready for prime time. Section III does the same for inertial fusion, concentrating mostly on lasers, and making the case that these are the only reasonable option at this point. Section IV reviews the nuclear issues, concentrating on fusion breeding and gives a possible road map for fusion to produce large scale power by mid century or shortly thereafter. Section V reviews the 'energy park', a sustainable approach to producing terawatts of economical, environmentally viable power for a world with 10 billion people. A fusion breeder produces fuel for about 5 thermal reactors, likely 5 LWR's, of equal power, and a fast neutron reactor, also of equal power, which burns the actinide wastes. Only thorium goes in, only electricity and/or manufactured liquid fuel go out. Section VI draws conclusions.

I will close this introduction with an anecdote. A few years ago I was at an international fusion workshop. The head of the fusion effort of a small European country told all he and his group were doing for ITER. In one of my own less than stellar moments, I jumped on him, saying that he was only getting lip service, and the larger European countries did not value his contribution. He answered that they are indeed a small, but important part of ITER. Then when I got up and gave my pitch for fusion breeding, he jumped on me and said only pure fusion made sense and breeding or any other nuclear option only was a waste of effort.

By serendipity, he and I rode together to the airport. First I apologized for my remarks, and admitted that it did indeed look like his group was doing important work. Then he went on to say that he actually understood that fusion breeding or some other hybrid approach was ultimately the only hope for ITER. I asked him why he landed on me like a ton of bricks. He said, I did not understand, the German Greens are very powerful, and with any hint of nuclear, they would go on the attack against ITER, and likely derail it.

This article has no concern for the sensitivities of the German Greens.

\section{Magnetic Fusion}

There are many different possible approached to magnetic fusion. How does one compare them? There are many different potential yardsticks, but we will choose two. The first is the triple fusion porduct $n T \tau$, where $n$ is the density in $\mathrm{m}^{-3}, \mathrm{~T}$ is the temperature in $\mathrm{keV}$, and $\tau$ is the energy confinement time in seconds. At fusion temperatures, the DT fusion reaction rate $\langle\sigma v\rangle$, is roughly proportional to the ion temperature squared. For instance at $10 \mathrm{keV}$, $\langle\sigma \mathrm{v}\rangle=1.1 \times 10^{-16} \mathrm{~cm}^{3} / \mathrm{s}$, at $20,4.2 \times 10^{-16}$. Since the fusion power per unit volume is $n_{D} n_{T} W\langle\sigma v\rangle$, where $W$ is the fusion energy per reaction, $14 \mathrm{MeV}$ for the neutron and 3.5 for the alpha particle, this power density is roughly proportional to $\mathrm{n}^{2} \mathrm{~T}^{2}$. However the input power density is simply $\mathrm{nT} / \tau$, so the ratio of fusion power to input power, the $\mathrm{Q}$ of the device is roughly proportional to $\mathrm{nT} \tau$.

Since the whole idea of magnetic fusion is to contain the energy of the plasma, the second obvious measure of a magnetic fusion device is how much energy $\mathrm{E}$ does the device confine in Joules. With these two measures of performance, we will compare the various magnetic confinement configurations.

We first discuss the tokamak, which is the main part of this section. Then we briefly discuss other confinement schemes. Not only is the tokamak way ahead of the other devices, many of these others have what appear to this author to be fatal flaws. These flaws are, in many cases, quite simple in concept and indeed appear to be irrefutable. The very simplicity of these flaws, combined with the many orders of magnitude in performance measure that separate these devices from tokamaks, argue very powerfully in favor of tokamaks. Alternative systems undoubtedly can provide a great deal of fundamental information on plasma confinement, but is this the goal? Is it worth the additional billions to achieve it? To this author, the goal is to achieve fusion breeding or pure fusion in the shortest possible time, and the way to get there is to concentrate on the device, which is, by many orders of magnitude, the closest to the goal.

This is not to say tokamaks are a slam dunk. There are serious obstacles that must be overcome before tokamaks can be viable fusion breeders, or pure fusion devices. However they have many fewer obstacles than any other configuration.

Tokamaks

\section{History and Development}

The worldwide magnetic fusion has concentrated on the tokamak approach for the last 40 years. Very briefly, a 

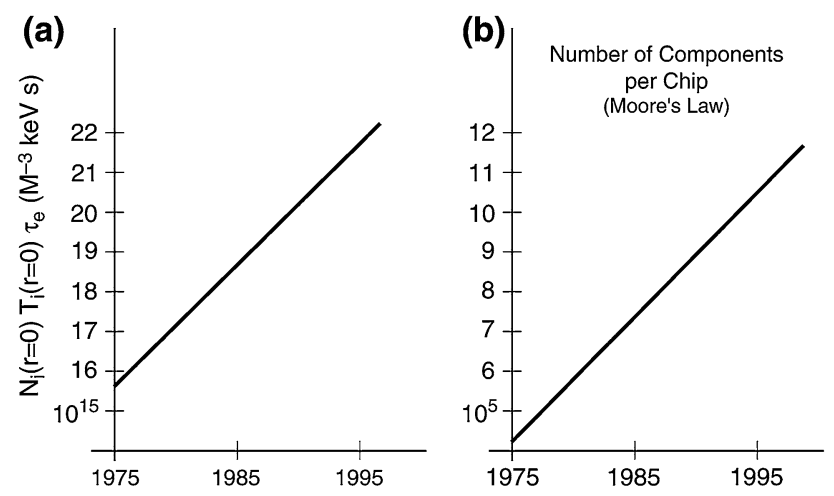

Fig. 1 The $n T \tau$ in $\mathrm{m}^{-3} \mathrm{keVs}$ for tokamaks as a function of year, compared to the number of transistors on a chip as a function of year from 1975 to 1995

tokamak is a toroidal plasma carrying a toroidal current, confined in part by a toroidal magnetic field. In various modern high performance tokamaks around the world, the major radius varies from less than a meter to more than $3 \mathrm{~m}$, the minor radius from 0.2 to more than $1 \mathrm{~m}$ and the toroidal field is typically between about 2.5 and $10 \mathrm{~T}$ (with $5 \mathrm{~T}$ being a estimate if one wishes to use a single parameter). Electron densities are in the range of $10^{19-20} / \mathrm{m}^{3}$, electron and ion temperatures between 1 and $15 \mathrm{keV}$ and plasma currents are typically in the Meg amp range. Generally today's tokamaks use copper toroidal field coils. However while satisfactory for pulsed experiments, these would be enormous power drains in continuous or high duty cycle operation. Hence there is wide agreement that superconducting coils would have to be used in any reactor. The plasmas is heated by Ohmic heating, but this is not nearly enough; supplementary heating is necessary. Usually neutral beams are used for heating, but various types of electromagnetic waves are also being considered.

There have been three large tokamak experiments using $40 \mathrm{MW}$ or more of neutral beam to power to tokamak, JT60 in Japan, JET in England, and TFTR in the United States; but TFTR has been decommissioned in 1998. Only the latter two have run with DT plasmas. In a brief digression, the author expresses the opinion that it was a great mistake to decommission TFTR. The logic might have been that it had achieved everything it could, but that logic did not convince the sponsors of JET and JT-60, and those tokamaks have gone on another 15 years and have achieved a great deal. The main effect of our decision is that the United States can no longer play in the big leagues in tokamak research. However the author is convinced that there is enough residual tokamak knowledge here that we can rejoin at any time. This article will propose that we do just that.

The tokamak effort has been incredibly successful. A thorough review of tokamak performance, up through the

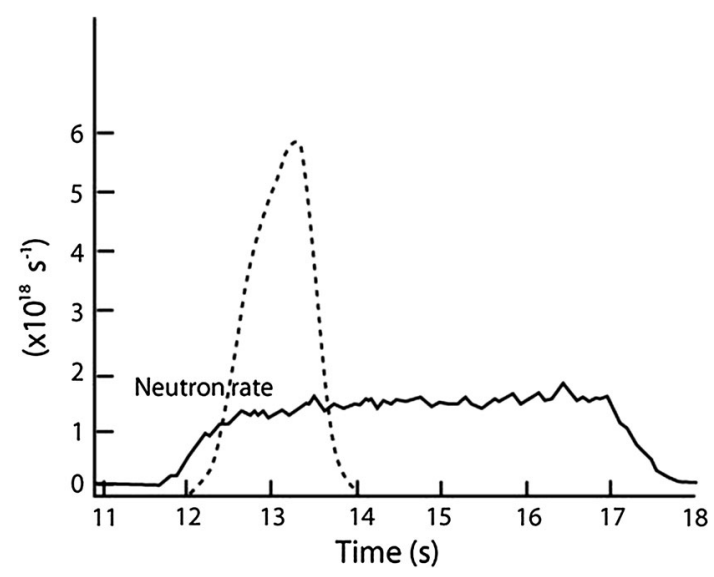

Fig. 2 Neutron production rate from JET as a function of time for steady state and hot ion modes of operation

late 1990s has recently been given by the author [5]. In Fig. 1a is shown a very rough plot of the triple fusion product as a function of year (much more detail is given in Ref. [5] ). In Fig. 1b is shown the number of transistors on a chip as a function of year (Moore's law) [32]. The latter has been called a " 25 year record of innovation unmatched in history". But the slopes of the two graphs are about the same. To this author, the period from about 1970 to about 2000 can be regarded as the golden age of tokamaks.

However there is one important difference between Fig. 1a, b. At every point along the curve in Fig. 1b, the semiconductor industry was able to produce something useful and profitable. Furthermore, after the late 1990s that curve kept advancing, while Fig. 1a leveled off. The tokamak program, despite its success, is still several orders of magnitude away from producing anything economically viable; and the cost of the follow on projects gets very high. However for tokamaks, the period of rapid advance shown in Fig. 1a corresponded to the period of constructing larger and large tokamaks. However there have been no large tokamaks built since, so the performance, as measured by the triple fusion product is about where it was in 1997. What has improved are other figures of merit, principally the discharge time, going from say a second to tens of seconds (in JT-60) [33-38].

Both TFTR and JET have operated with DT plasmas, so they have produced $14 \mathrm{MeV}$ neutrons in appreciable quantities. In a particular shot, JET has generated about $10^{19}$ in a $1 \mathrm{~s}$ pulse $[39,40]$, or generated about $20 \mathrm{MJ}$ of neutron energy, giving a $\mathrm{Q}$ of about 0.5 . JT-60, in deuterium plasma has produced equivalent $Q$ 's higher than unity $[33,34]$ by using what they called a $\mathrm{W}$ shaped diverter. However, for one reason or another, these plasmas all terminated prematurely (after about $1 \mathrm{~s}$ ). In plasma which persists as long as the beam, the Q is much smaller, typically about 0.2. In Fig. 2, redrawn from Ref [39] are shown 


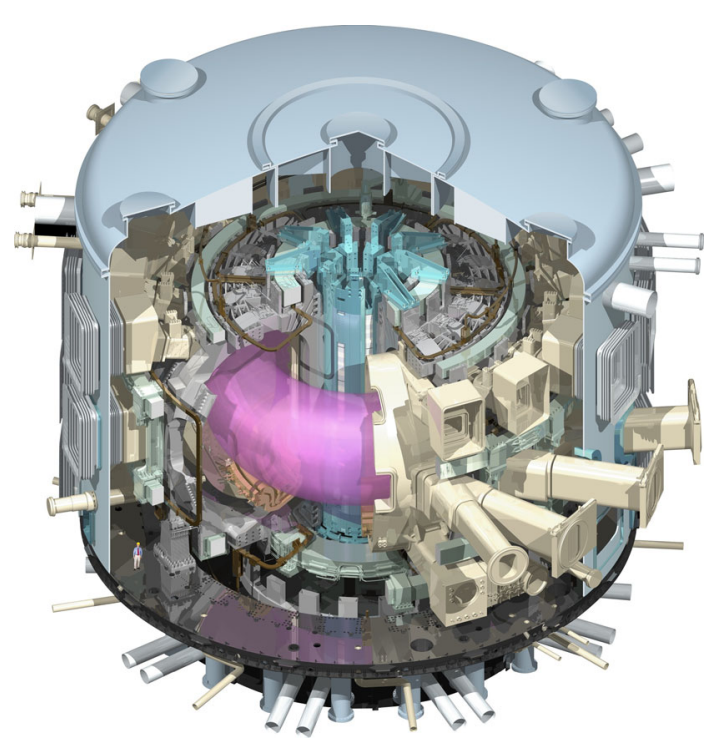

Fig. 3 A schematic of ITER take from its web site (Color figure online)

neutron rates from two separate discharges in JET, one which terminates and one which persists. It would seem that one very important milestone for both JET and JT-60 would be to see if it can achieve a persistent $Q \sim 1$ discharge.

The JT-60 web site specifies that it has achieved a triple fusion product of $1.6 \times 10^{21} \mathrm{~m}^{-3} \mathrm{keVs}$, and contains plasma energy of about $9 \mathrm{MJ}$. The web site shows the progress of $\mathrm{nT} \tau$ as a function of year. It shows a large advance, up to the late 1990s, followed by about 15 years of flat line.

\section{The International Tokamak Experimental Reactor (ITER)}

Since follow on experiments to TFTR size tokamaks get so large and expensive, the world has made a decision to cooperate on the construction of a single large reactor ITER. It has had a troubled political and economic history. Its origin was in the 1985 summit meeting between President Ronald Reagan and General Secretary Mikhail Gorbachev. They proposed cooperating on a single large joint tokamak. It was originally called INTOR for international torus. Design work began on it but few decisions were made. In 1999, the project was to be an $8 \mathrm{~m}$ major radius machine, in which about $150 \mathrm{MW}$ of neutral beam heating would generate about $1.5 \mathrm{GW}$ of neutron power for a $\mathrm{Q}$ of about 10 [28]. The cost then was estimated at about $\$ 20$ billion, $\$ 10 \mathrm{~B}$ for construction, and then another $\$ 10 \mathrm{~B}$ for operating expenses over a 10 years period. The international partners were the Soviet Union (and subsequently Russia), the United States, the European Community, China, Japan and South Korea.
Subsequently the United States, deciding that the project was too expensive, pulled out. The remaining partners ultimately decided to agree on a smaller, less expensive machine. The new ITER was to be a $6 \mathrm{~m}$ major radius machine which would use about $40 \mathrm{MW}$ of beam power to produce about $500 \mathrm{MW}$ of fusion power [22]. The cost was estimated at about $\$ 10 \mathrm{~B}$, now $\$ 5 \mathrm{~B}$ for construction and $\$ 5 \mathrm{~B}$ for operation over 10 years. The United States rejoined in 2003. However there was now another controversy; where to build it. Both the European community and Japan put in strong proposals to host it. The United States, Japan and Korea voted for Japan, while Europe, Russian and China voted for Europe (Carderache, France). With the vote tied, there was a standoff, which lasted for several years. Finally in 2005, the partners decided to construct ITER in France. By this time, India joined the consortium, bringing the total number of partners to 7. Shown in Fig. 3 is a schematic of ITER taken from its web site (www.iter. org).

However with agreement on the site, ITER's problems were far from over. The construction cost was greatly underestimated. The original 5B euro estimate in 2006 has more than tripled to over $16 \mathrm{~B}$ euros in 2010 , and the completion date has slipped from 2016 to 2019 [23]. This undoubtedly motivated Senator Diane Feinstein's comment cited in the introduction. However at least since 2010, according to the ITER web site, the completion date has not slipped any further.

Whether construction of ITER was a wise decision or not, ITER is what we have got. The only realistic option for magnetic fusion is to get it to work as well as possible. On the ITER web site, there is talk of a DEMO as a follow on project. This would potentially generate electricity for the grid. However as we will show in the next section, in order to do so, this DEMO must get over a series of obstacles, which have constrained tokamak operation for half a century. It is extremely important that while these obstacles prevent pure fusion, they do not prevent fusion breeding.

\section{Conservative Design Rules (CDR's) for Tokamaks}

The Rules Tokamak operation is subject to four very simple parameter constraints, which are well-grounded in theory, extensively confirmed by experiment, and generally accepted by the fusion physics community. Although these constraints have been known for decades, there has not been much discussion of their impact collectively on fusion reactor operation. We have coined the term "Conservative Design Rules" (CDRs) to describe this set of constraints, and in Ref. [8] we discussed in detail the limits that these rules, taken collectively, impose on fusion power output. We emphasize that the Conservative Design Rules are not controversial. The paper [8] has been in the literature 
5 years; its conclusions have not been challenged. The author has discussed the CDRs in seminars at MIT, University of Maryland, NRL, and APS headquarters, again without challenge. Thus, there is a heavy burden of explanation and proof on any proponent of pure fusion who assumes reactor performance in excess of the CDRs.

The other thing about conservative design rules is their simplicity. One does not have to know about any of the complexities of tokamaks; fishbones, transport barriers, grassy ELM's, ITGI's, density pedestals, etc. In fact the Sam Cooke approach ("Don't know much about tokamaks...") suffices. There are surely much more complicated physical effects further limiting tokamak behavior (i.e. the afore mentioned), but conservative design rules bound all of these, are very simple, and are well established in the tokamak science base. But they have not been emphasized in the literature, nor have their very important implications for fusion been discussed.

It is important to note that conservative design rules have nothing to do with transport. Good transport cannot improve things, bad transport can only make things worse. In fact even if there is no input power, for instance an ignited tokamak, conservative design rules still place the same limits on the fusion power a tokamak can produce. They almost certainly prevent economical pure fusion.

The conservative design rules were discussed in detail in Ref. [8]. Here we will give a shortened version and leave additional details to the reference.

Any tokamak run as a reactor can in all likelihood withstand existing levels of transport. What it cannot tolerate are many (or even any) major disruptions. Thus in the relevant parameter space, there is a boundary separating regions where a tokamak may disrupt. A commercial reactor should operate as far from this red zone as possible, thereby motivating the author's term 'conservative design rules'. While disruptions are still not yet fully understood, they are almost certainly rooted in MHD (ideal and resistive) effects in the plasma. MHD instabilities are driven by the current and pressure gradient. The first and most important design principle concerns the plasma beta.

To simplify the discussion here, we will assume the plasma has circular cross section in the poloidal plane, more general configurations are discussed in Ref. [8].

Troyon and Gruber [41, 42] achieved a theoretical breakthrough in understanding the pressure limit. They determined that the maximum beta was governed by what they called the maximum normalized beta $\beta_{\mathrm{N}}$. In terms of $\beta_{\mathrm{N}}$, the volume averaged plasma beta $\beta$ was given by

$\beta=10^{-2} \beta_{\mathrm{N}} \mathrm{I} / \mathrm{aB}$

where $\mathrm{I}$ is the current in Megamps, $\mathrm{a}$ is the minor radius in meters, and $\mathrm{B}$ is the toroidal field in teslas. Their calculations gave a value for $\beta_{\mathrm{N}}$, and from this $\beta$ could be determined. If the plasma had no wall stabilization, they found a maximum stable $\beta_{\mathrm{N}}$ of about 2.5 or a little greater; and with strong wall stabilization, it might be as large as 5 .

In our conservative design, we will neglect wall stabilization. In a DT tokamak reactor, the wall is doing enough; absorbing and multiplying neutrons, dissipating heat from fast ions and radiation, being one end of a heat exchanger and breeder of ${ }^{233} \mathrm{U}$ and/or T, etc. Furthermore tokamaks always operate with either divertors or limiters, so the wall cannot get that close to the plasma in any case. Hence we take Troyon's most conservative value, since it will be furthest from the disruption threshold. Thus we take for our first principle of conservative design the condition that $\beta_{\mathrm{N}}$ is 2.5 or less.

To make further progress while keeping our analysis as simple as possible, we assume a density and temperature profile for the plasma. For circular cross section with minor plasma radius a (more complicated geometries are analyzed in [8]), we take parabolic profiles

$n_{e}=n_{o}\left[1-\left(\frac{r}{a}\right)^{2}\right]$

$T_{i, e}=T_{i, e o}\left[1-\left(\frac{r}{a}\right)\right]^{2}$

where $n_{e}$ is the electron density, assumed to be twice the deuterium and tritium density and $\mathrm{T}_{\mathrm{i}, \mathrm{e}}$ is the ion (electron) temperature. The spatially average density is $n_{o} / 2$. The pressure is the product of the two, and the spatially averaged pressure is $n_{o}\left(T_{e o}+T_{i o}\right) / 3$. Of course there may be effects from different profiles but they should not be major. For instance at the average beta, the center temperature may be higher (giving more fusion power) but cover a smaller average volume (giving less fusion power). In fact most profiles do not fill out nearly as much as a parabolic profile does, so the parabolic profile choice is rather optimistic.

If density and temperature are totally unrestricted, $\langle\sigma v\rangle$, as a function of temperature, has a broad maximum at a temperature of $T_{i} \sim 50 \mathrm{keV}$. However if $\beta$, that is total plasma pressure is held constant the maximum is at lower temperature, because this means the density is higher. Since $\beta$ depends on $T_{e}+T_{i}$, whereas the fusion rate depends only on $T_{i}$, we must make some assumption here. We assume $T_{e}=T_{i} / 2$, as is often characteristic of today's beam heated tokamaks. (If the temperatures were equilibrated, the neutron power would be lower, obviously one can do this calculation for any electron temperature).

Calculating the neutron power by integrating over volume $\langle\sigma v\rangle$ times the tritium times the deuterium density times the neutron energy, we find that the it is 


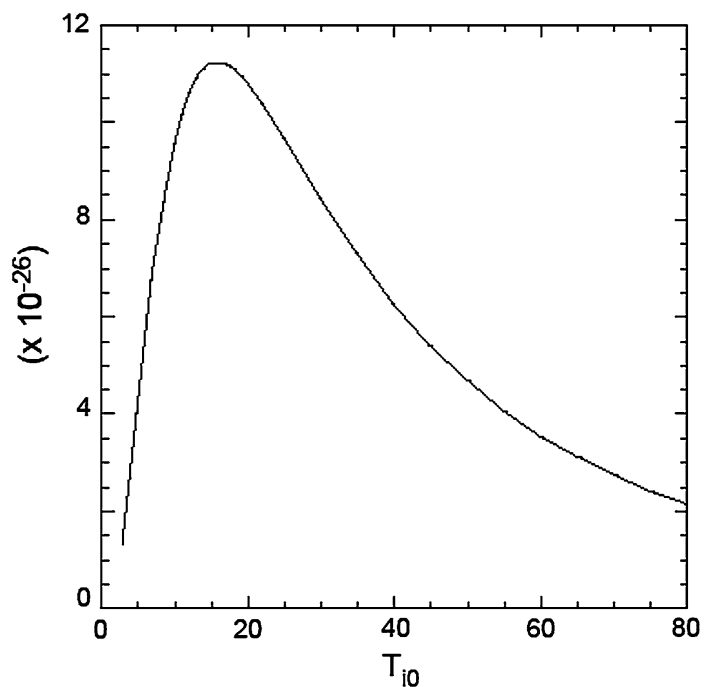

Fig. 4 A plot of the quantity $\chi\left(T_{i o}\right) / T_{i o}^{2}$ as a function of central ion temperature. It is proportional to the neutron power for a plasma of fixed pressure

$P_{n}=2.2 \times 10^{22}(2 \pi R)\left(2 \pi a^{2}\right) \frac{n_{o}^{2}}{4} \chi\left(T_{i o}\right)$

where we have assumed $n_{D}=n_{T}=n_{o} / 2$ (recall the units of $\mathrm{n}_{\mathrm{o}}$ are $10^{20} \mathrm{~m}^{-3} ; \mathrm{P}_{\mathrm{n}}, \mathrm{MW}$; and lengths, meters; and temperatures, $\mathrm{keV}$ )

$\chi\left(T_{i o}\right)=\int_{0}^{1} u d u<\sigma v\left(T_{i}(u)\right)\left(1-u^{2}\right)^{2}$

If beta is specified, then the density is proportional to $\mathrm{T}^{-1}$. The function $\chi\left(\mathrm{T}_{\mathrm{io}}\right) / \mathrm{T}_{\mathrm{io}}^{2}$ is plotted in Fig. 4. It has a maximum at $\mathrm{T}_{\text {io }}$ of about $15 \equiv \mathrm{T}_{\mathrm{io}}(\beta)$. To get the average reactivity for the plasma, just multiply the ordinate by $\mathrm{T}_{\mathrm{io}}^{2}$. Now expressing the density at which the maximum fusion rate occurs, we get

$\mathrm{n}_{\mathrm{o}}(\beta)=\frac{\beta_{\mathrm{N}} \mathrm{IB}}{2 \mathrm{aT}}$

To determine $n_{o}(\beta)$, note that the maximum $\beta_{N}$ can be is 2.5 , consistent with out first design principle.

Now we introduce the second conservative design principle. Decades of plasma experience have shown the tokamaks cannot operate at densities above the Greenwald limit $[43,44])$. While this is more of an empirical law than one grounded in solid theory, it has held for two decades already. The Greenwald density limit (equal to $\mathrm{n}_{\mathrm{o}} / 2$ for our assumed parabolic density profile) is given by

$\mathrm{n}_{\mathrm{G}}=\frac{1}{\pi \mathrm{a}^{2}}$

However the failure mode in approaching the Greenwald limit is often a shrinking of the plasma profile followed by a major disruption. Since major disruptions are basically intolerable in any reactor, we take as our second principle of conservative design that the density cannot be above $3 / 4$ of the Greenwald limit. To simplify the discussion, we do not consider further the Greenwald limit here; it places an additional restriction on the density as fully discussed in Eq. (8). Considering only the beta limited density gives a good idea of the constraints the tokamak operates under.

Both density limits depend on the current, and if this could increase indefinitely, there would be no problem. But from ideal and resistive MHD, we know that $\mathrm{q}$, the safety factor equal to $\mathrm{Br} / \mathrm{B}_{\mathrm{p}} \mathrm{R}$, where $\mathrm{B}$ is the toroidal field, $\mathrm{B}_{\mathrm{p}}$ is the poloidal field, at the limiter or diverter, $r=a$, is nearly always greater than three. This then is the third principle of conservative design, namely that $\mathrm{q}(\mathrm{a})>3$. For tokamaks of circular cross section, the relations then simplify considerably since one can express q(a) very easily in terms of current. For circular cross section, the beta limited density is simply

$\mathrm{n}_{\mathrm{o}}(\beta)=\frac{5 \mathrm{aB}^{2} \beta_{\mathrm{N}}}{2 \mathrm{Rq}(\mathrm{a}) \mathrm{T}_{\mathrm{io}}(\beta)}$

and $\mathrm{q}(\mathrm{a})$ is given by

$\mathrm{q}(\mathrm{a})=5 \mathrm{a}^{2} \mathrm{~B} / \mathrm{IR}$

In this case, the maximum density depends only on magnetic field and aspect ratio(or geometry if the cross section is not circular) as well as $\beta_{\mathrm{N}}$, taken to maximize at 2.5 , and $\mathrm{q}(\mathrm{a})$ taken to minimize at 3. Equation (6), as well as Eq. (3a) and Fig. 4 then give the maximum fusion power any tokamak can generate if it is limited by conservative design rules.

Notice that confinement does not come into these principles at all. This is not to say it is unimportant; the confinement and transport determine the external power needed to maintain the plasma profiles. However even if there were no losses (or else for instance an ignited plasma), these three design rules put serious constraints on what a tokamak can and cannot do. Good confinement cannot make things better, bad confinement can only make them worse.

We now discuss the fourth conservative design rule, the size of the blanket. For ITER and Large ITER, reactor sized tokamaks, our assumption is that the existing designs have room for an appropriate blanket which absorbs neutrons, breeds tritium, handles the heat load, etc. But if one wants to build a smaller tokamak, such as the scientific prototype, which we will discuss shortly, how thick does the blanket have to be? Here, the author has little expertise so only very qualitative matters are considered. The mean free path of neutrons with energies between about 1 and $14 \mathrm{MeV}$ is about $15 \mathrm{~cm}$ in lithium, and about $6 \mathrm{~cm}$ in beryllium and thorium. All of these are important blanket 


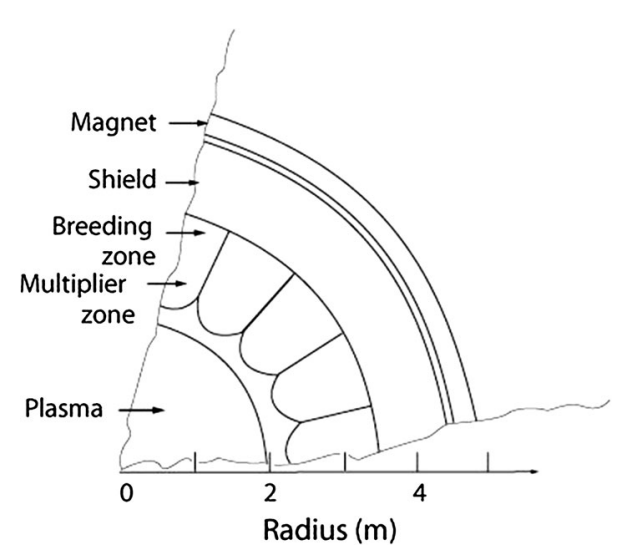

Fig. 5 A schematic of a tokamak and its blanket showing the width of about a meter and a half

materials for either pure or hybrid fusion. The mean free path for breeding and slowing down is even longer. Obviously the blanket has to be many mean free paths thick so as to prevent neutron leakage out the back, if one desires long life of the machine. Also one clearly desires to prevent activation of materials behind the blanket. Behind the blanket is usually a neutron shield, which itself is not thin.

Many references on fusion hybrids show schematics of the reactor along with the $2 \mathrm{~m}$ man standing along side it, and the blanket is about his size. Rarely are dimensions given. One exception is a rough schematic of a blanket shown in Ref. [45], reproduced here in Fig. 5. In this schematic, the blanket is between 1.5 and $2 \mathrm{~m}$ thick, and presumably there is no long term neutron leakage or activation of materials in back. Lidsky [45] when discussing a blanket for fission suppressed thorium cycle postulates a blanket $80 \mathrm{~cm}$ thick for just the fertile material. Hence, as a very rough rule of thumb, we will specify that the blanket has to be $1.5 \mathrm{~m}$ thick. We will call this the fourth conservative design principle. It applies only where one wishes to design a small (i.e. less than commercial size) reactor, and it imposes a certain minimum size on the experimental device which strives for steady state operation with DT. This design principle is more approximate than the other three, and it may be possible to design thinner blankets.

To summarize, the conservative design rules are:

$\beta_{\mathrm{N}}<2.5$

$\mathrm{n}_{\mathrm{o}}<1.5 \mathrm{I} / \pi \mathrm{a}^{2}$

$\mathrm{q}(\mathrm{a})>3$

Blanket thickness $>1.5$ meters

That is it. What could be simpler? All one needs is the toroidal field, temperature ratio and geometry, and conservative design rules determine the maximum fusion power a tokamak can produce.
Once the magnetic field and geometry are specified, this specifies the minimum q(a), Eq. (8c), that is, the maximum current. If the tokamak is pressure limited, Eq. (8a) specifies the maximum total pressure, $\mathrm{n}_{\mathrm{o}}\left(\mathrm{T}_{\mathrm{eo}}+\mathrm{T}_{\mathrm{io}}\right) / 3$. Take the ion temperature of $15 \mathrm{keV}$, make an assumption of the electron temperature and one has the $n_{o}$, and from $n_{o}$, the neutron power. For a circular cross section and beta limited density, the formula for the maximum power allowed by conservative design rules is very simple;

$\mathrm{P}(\mathrm{MW})=0.11[\mathrm{a}(\mathrm{m}) \mathrm{B}(\text { Tesla })]^{4} / \mathrm{R}(\mathrm{M})$

Here we have assumed $T_{i}=2 T_{e}$, as is typical for today's beam heated tokamaks. However temperature equilibration is likely a more reasonable assumption for a reactor. Then, since more of the allowed pressure is taken up by nonreacting electrons, the fusion power is less. The density is reduced by $3 / 4$ and the power by $9 / 16$. This then gives the maximum fusion power a tokamak can give. More complicated geometries are treated in [8], but very roughly, the power is increased by the elliptical elongation factor $\mathrm{k}$.

If the ion temperature could be maintained at twice the electron temperature, it would certainly be advantageous. One way this might be accomplished is through what is called alpha channeling [46, 47]. Waves and particles in a tokamak interact in a complicated way in which the interacting particles move on some prescribed path in the six dimensional phase space. The idea of alpha channeling is to find a wave or set of waves, which move the alpha particles from the center of the tokamak to the edge, while at the same time significantly lowering their energy. The energy thus goes from the alphas to the waves, which can then be used for other purposes. The most obvious purposes are current drive and heating of the plasma ions. (The alpha particles preferentially heat the electrons by collisions.) In this way it might be possible to maintain an ion temperature twice the electron temperature in a reactor. As a total reach, it might be possible convert these waves to other waves which can exit the plasma and thereby harvest their energy directly, but this is obviously very speculative. So far preliminary thought is to use ion Bernstein waves driven by lower hybrid waves, and Alfven waves.

If the density is Greenwald limited rather than beta limited, the maximum power is reduced [8]. Basically where the density has to be lower than the beta limited optimum, the fusion power optimizes if the ion temperature is higher than $15 \mathrm{keV}$. By applying these conservative design rules to existing and proposed tokamaks in the next few sections, we will see that the maximum neutron power that can be expected from any proposed tokamak is well below the minimum level needed for economical power production.

Unlike the argument given in the Introduction where driver power and its efficiency, and output power and its 
efficiency in converting to electricity, were considered, conservative design rules are independent of all of that. They show the maximum power a tokamak can deliver, even a burning plasma with no power to drive the plasma or current $(\mathrm{Q}=$ infinity). Let us make this extremely optimistic assumption. However even then, the capital cost involved in building such a tokamak such as Large ITER, we optimistically assume at least $\$ 25 \mathrm{~B}$ for a $500 \mathrm{MWe}$ reactor, and likely a large operating cost to boot, will in practice render it unsuitable for economical power production. But we will also see that tokamak breeders can function well within these limits, even though their Q is 'only' 10 , well below infinity.

Recent Tokamak Experiments in the Light of These Design Principles We summarize results here for TFTR and JT60 in the light of conservative design rues. Results for other tokamaks, including JET, D3-D and Asdex are summarized in [8]. No tokamak up to now has exceeded the limits imposed by conservative design rules; in fact conservative design rules overestimate fusion by at least a factor of two in all cases.

TFTR: Results from TFTR were summarized in [48] Briefly it achieved spectacular results when operating in the hot ion supershot mode. These have peaked profiles, and the beam is important for both heating and fueling the plasma. It achieved a maximum fusion power of $10 \mathrm{MW}$ for perhaps half a second. However it terminated by rapidly dumping all or a significant part of the plasma energy. The major radius was $2.6 \mathrm{~m}$, the limiter radius was $0.9 \mathrm{~m}$ and the magnetic field was over 5T. This is all that is needed to get maximum parameters of the device according to the conservative design principles.

In Ref [48] there was a table of parameters of 4 supershots. A portion of the table is presented in Table 1. The rows in bold are from Ref [48], the rows in ordinary type are from conservative design principles. The central ion temperature is much higher than the optimum value of $15 \mathrm{keV}$, but the beta is still consistent because the hot part of the plasma is so narrow compared to the parabolic profile we have been assuming. In fact, their measured $\beta_{\mathrm{N}}$ 's are smaller than what we have assumed in the conservative design. While they do not give q(a), for their circular cross section one can estimate it easily enough. In all cases $q(a)>3$, so that the results are consistent with conservative design principles in this respect. There are two rows for the calculation of the central density from conservative design rules for $q(a)=3$ and $\beta_{N}=2.5, n_{o}(\beta)$ and $n_{o}(G)$. For TFTR, the former is slightly smaller, so the density is beta limited, not Greenwald limited. In the last row of the table is given neutron power from Eq. (9). Notice that the neutron power per the conservative design is at least double the actual neutron power observed. Hence even though
Table 1 Summary of parameters of hot ion shots in TFTR (bold type). Prediction of beta and Greenwald limited central density and predicted neutron power according to conservative design rules (regular type)

\begin{tabular}{lll}
\hline Shot number (expt) & $\mathbf{2}$ & $\mathbf{3}$ \\
$\mathbf{B}$ & $\mathbf{5 . 1}$ & $\mathbf{5 . 6}$ \\
$\mathbf{I}$ & $\mathbf{2 . 5}$ & $\mathbf{2 . 7}$ \\
$\mathbf{n}_{\mathbf{o}}$ & $\mathbf{0 . 8 5}$ & $\mathbf{1 . 0 2}$ \\
$\mathbf{T}_{\mathbf{i o}}$ & $\mathbf{4 4}$ & $\mathbf{3 6}$ \\
$\boldsymbol{\beta}_{\mathbf{N}}$ & $\mathbf{2}$ & $\mathbf{1 . 8}$ \\
$\mathbf{q}(\mathbf{a})$ & $\mathbf{3 . 2}$ & $\mathbf{4}$ \\
$\mathbf{P}($ neutron$)$ & $\mathbf{9 . 3}$ & $\mathbf{1 0 . 7}$ \\
Shot number (conservative design, $\mathrm{q}(\mathrm{a})=3$ and $\left.\beta_{\mathrm{N}}=2.5\right)$ & \\
$\mathrm{n}_{\mathrm{o}}(\mathrm{G})$ & 1.5 & 1.7 \\
$\mathrm{n}_{\mathrm{o}}(\beta)$ & 1.25 & 1.5 \\
$\mathrm{P}($ neutron) $(\mathrm{MW})$ & 21 & 31 \\
\hline
\end{tabular}

TFTR managed to get a much higher ion temperature than 15 , it did not help very much. The reaction rate was higher in this region of high temperature, but the density was lower, and the volume of strongly reacting plasma was also smaller; the net effect being less neutron power than the conservative design rules would specify. Thus for TFTR, the conservative design rules over estimate the fusion power, typically by at least a factor of two.

In Ref. [8] we show that conservative design rules also overestimate the neutron power in JET, in both hot ion and long lived modes, by at least a factor of 2 .

$J T-60 U$ : JT-60 and more recently its upgrade JT-60U is the largest of the tokamaks, but so far, has not operated with DT (http://www-jt60.naka.jaea.go.jp/english/index-e. $\mathrm{html}$ ). Its parameters are a major radius of $3.4 \mathrm{~m}$, a minor radius of $1.2 \mathrm{~m}$ (to the vacuum wall) and an elongation of about 1.4. The maximum magnetic field is about $4.2 \mathrm{~T}$. Although JT-60U has not yet operated with DT, it has operated with DD plasmas, and from the DD neutron rate, they extrapolate to get the DT rate. In all their reported data, as regards $\beta_{\mathrm{N}}$ (virtually always equal to or $<2.5$ ) $\mathrm{q}(\mathrm{a})$ (virtually always $>3$ ) and $\mathrm{n} / \mathrm{n}_{\mathrm{G}}$ (virtually always $<0.75$ ), their results are consistent with the conservative design rules.

A great deal of their earlier effort consisted in developing what they called a $\mathrm{W}$ shaped diverter. Here, they reported their largest amount of fusion power, with the equivalent $\mathrm{Q}$ in a DT plasma going above unity, and with a great deal of the improvement coming from the new diverter. Figure 6 redraws their plot of equivalent $\mathrm{Q}$ vs current from these references. It reaches a maximum of 1.25 , nearly double their previous results. However they point out that these are all transient results. In quasi steady operation, their DT equivalent Q's were below 0.2. This result is similar to the experience of JET. 
(a)

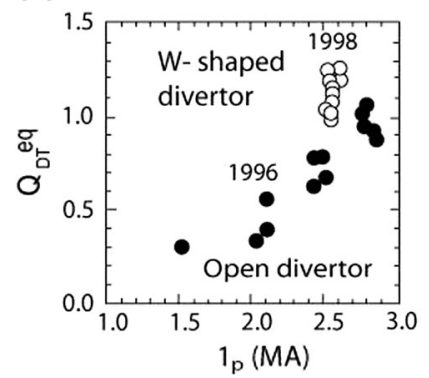

(b) $\square$ quasi-steady $>5 \mathrm{t}_{\mathrm{E}}$

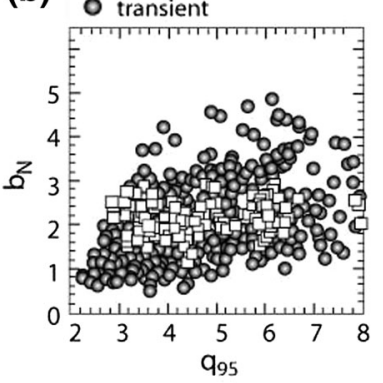

(c)

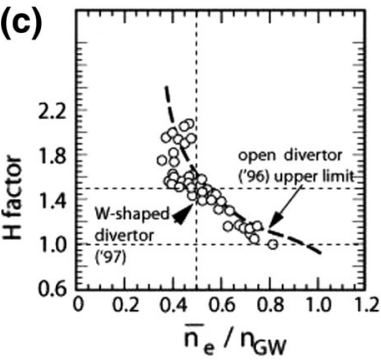

(d)

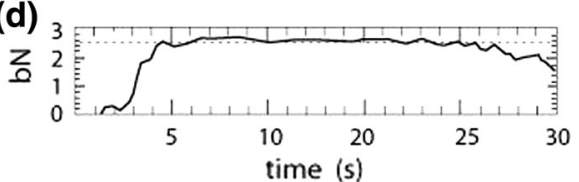

Fig. 6 Some JT-60 data confirming conservative design rules. A plot of DT equivalent $\mathrm{Q}$ as a function of current for JT- 60 for normal and W shaped divertors. A scatter plot of tokamak operation points in the parameter space of $\mathrm{q}(\mathrm{a})$ and normalized beta. Long lived discharges only operate in the region specified by conservative design rules. A plot of $\mathrm{H}$ factor as a function of density over Greenwald density, confirming another aspect of conservative design rules. A plot of normalized beta as a function of time in a long lived discharge

In their results for quasi steady plasmas, plasmas lasting longer than 5 times the energy confinement time, all their $\mathrm{q}(\mathrm{a})$ 's were greater than 3 and all their $\beta_{\mathrm{N}}$ 's were $<2.5$. A scatter plot of their data is shown in Fig. 6.

Regarding density in their earlier results, they were always below the Greenwald limit. In Fig. 6 is shown a redrawn plot of their $\mathrm{H}$ factor, the fractional increase in confinement time when they operate in the $\mathrm{H}$ mode, as a function of $\mathrm{n} / \mathrm{n}_{\mathrm{G}}$. They have a single point at 0.8 , at the worst confinement, and virtually all of their data is for $0.4<\mathrm{n} / \mathrm{n}_{\mathrm{G}}<0.6$.

In their later results, they emphasized long time operation. This involved getting bootstrap current of over $50 \%$ sustained for a long time and a $\beta_{\mathrm{N}}$ sustained for over 20s. Shown in Fig. 6 is a plot of $\beta_{\mathrm{N}}$ as a function of time is redrawn. While sustained for long time, it is still no greater than 2.5. Their q(a)'s were everywhere greater than 3 , and their maximum densities reported were at about $0.5 \mathrm{n}_{\mathrm{G}}$.

The Upshot To summarize, the conservative design rules are very well based in theory and so far have constrained tokamak operation. In fact so far, as regards neutron production, a tokamak is doing well to achieve half the neutron rate specified by conservative design rules. To get powers like $3 \mathrm{GWth}$, as needed in a commercial reactor, but in a tokamak smaller, much higher $\mathrm{Q}$, and less expensive than large ITER would stretch conservative design rules well beyond the breaking point. This then is the basis for the author's assertion that commercial pure fusion reactors based on tokamak configurations are unlikely, at least until one can find a way around conservative design rules. However as we will show shortly, a breeding tokamak can operate well within the limits of conservative design rules.

\section{Disruptions and Their Implications}

To get an appreciation of the disruption problem tokamaks have, it is instructive to look at the energies involved. In the case of hot ion modes, JT-60, JET and TFTR typically dump about $15 \%$ of the plasma energy abruptly on the walls. As JT-60 confined about $10 \mathrm{MJ}$, this means in these partial disruptions, about $1.5 \mathrm{MJ}$ is dumped, presumably mostly in the form of radiation and energetic ions and electrons. This is significant energy to dump in an uncontrolled manner, nearly a pound of TNT.

In a worst case scenario, if the plasma density is sufficiently low, the disruption energy could be, and has been manifested as relativistic electron ring. It could have much more than $1 \mathrm{MJ}$ energy. Once formed, there is nothing in the plasma to stop it, it will eventually hit the wall; and this could be enormously destructive.

But this is only for a partial $15 \%$ disruption. Major disruptions dump all of the energy of both the plasma (10 MJ in JT-60) and poloidal field (about the same as the plasma energy), so in this case about $20 \mathrm{MJ}$ of energy, in one form or other, are suddenly dumped on the wall. This is about $1.25 \%$ of the total magnetic field energy for each channel (plasma and current) for about $2.5 \%$ total. The plasma beta is likely quoted as considerably larger than $1.25 \%$, but then there is a good bit of magnetic field energy outside the plasma.

To estimate the energy available for disruptions in future devices, we will take as a rule of thumb that it is $2.5 \%$ of the total magnetic field energy. Now the energies available get serious. For ITER it is about $160 \mathrm{MJ}$, about the energy of an 80 pound bomb, and for large ITER, which this paper sees as an optimal end product, it is $550 \mathrm{MJ}$, the energy of nearly a 300 pound bomb. If more energy is stored in the plasma than our $2.5 \%$ of total magnetic energy, this is good for fusion, but makes disruptions still more dangerous.

But this is only the beginning of the problem. An 80 pound bomb equivalent going off in the confined space of 
Fig. 7 The disruptivity in JET as a function of Greenwald fraction and $1 / \mathrm{q}(\mathrm{a})$. There is an abrupt jump once conservative rules are violated
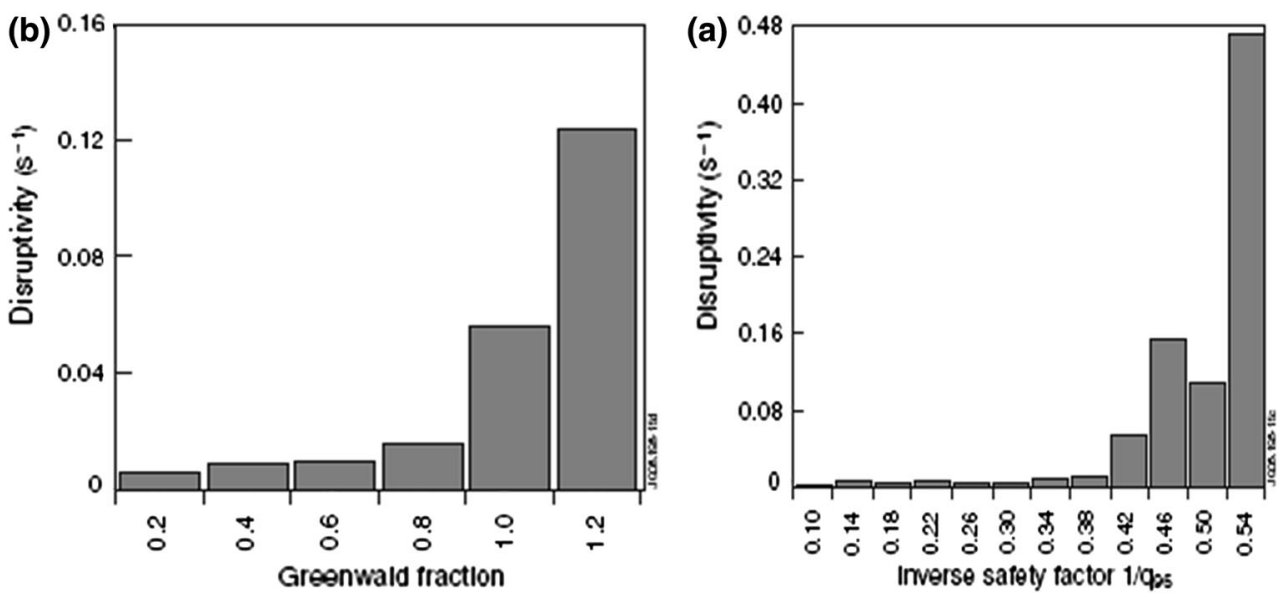

ITER might cause the superconducting toroidal field coils to uncontrollably quench. This could happen. It has happened in the Large Hadron Collider in CERN, bringing the accelerator down for a year. However the CERN tunnel has a huge volume compared to the interior of ITER. An uncontrolled quench in ITER would turn the 80 pound bomb into a 3200 pound bomb. It is unlikely that the building, or much around it could survive. It is important to note that ITER stores an enormous amount of energy.

But hasn't JT-60 shown that tokamaks can have very long pulses? See Fig. 6 for example. The answer is yes and no. Tokamaks can have very long pulses, but that certainly does not mean that they never disrupt. A very interesting statistical analysis of disruptions on JET has recently been published [49]. One of their important figures of merit is the disruptivity, the rate of disruptions in $\mathrm{s}^{-1}$, as a function of various parameters. Shown in Fig. 7 are disruptivities vs inverse q(a) and density over Greenwald density. There is a similar curve for disruptivity vs normalized beta.

There are two important take conclusions from this data. The first is that it confirms conservative design rules. Disruptivities rise sharply, by well over an order of magnitude as conservative design rules become violated. Secondly, the harmless looking disruptivities at low normalized beta, reciprocal $\mathrm{q}$ and density are not harmless at all. A disruptivity of $10^{-2}$ means a disruption every 2 min! Clearly this is unacceptable in a reactor.

Probably the most important job for both ITER and the scientific prototype (to be discussed shortly) is to find a fusion relevant regime where the disruption rate is close enough to zero that a reactor is possible. Clearly this will be much easier to do within the confines of conservative design rules, where a breeder can operate. As of now, there is no reason to believe that a disruption free regime exists outside of the conservative design rules where a pure fusion reactor must run.

A large airplane at speed and altitude has enormous kinetic and gravitational potential energy (in fact about the same as the stored magnetic energy in Large ITER), but people are inside, and the aircrew is able to control it. This is a reasonable analogy for tokamaks, and this author's expectation is that its stored energy also can ultimately be safely controlled, but only within the constraints of conservative design rules.

\section{The Scientific Prototype and Neutron Power of Various Tokamaks}

In all his work, the author has argued [5-10, 50] that the next logical step for the American Magnetic Fusion Energy program is a steady state tokamak, called the scientific prototype, about the size of TFTR, run with a DT plasma, achieves $Q \sim 1$ and which breeds its own tritium. After all tritium self sufficiency ultimately is absolutely essential, for either pure fusion or fusion breeding. If we do not tackle it now, then when will we? The scientific prototype is not some small thing to add to the American base MFE program; rather it is a very large project which would replace the entire base program. The tremendous resource of theoretical, experimental and computational expertise in the American base program would be refocused on this single large project. If the $\sim \$ 350 \mathrm{M}$ per year that comprises the base program were focused on the scientific prototype for 15 years, that would make over $\$ 5 \mathrm{~B}$ available, not much less than the cost of a 1 GWe LWR.

There are two crucial plasma physics problems, which must be solved by the scientific prototype. The first is steady state operation. Ideally this would mean no Ohmic current drive. However in practice, a small amount of Ohmic drive may be unavoidable, and may even be acceptable if the plasma on time is long compared to the off time necessary to recharge the transformer. This is particularly the case if the tokamak is viewed principally as a fuel factory and only secondarily as an on line power source. JT-60 has already demonstrated discharge durations of much more than 5 energy confinement times at the 
required normalized betas, q(a)'s, and density. One of their runs, at a normalized beta of 2.5 , for half a minute is shown in Fig. 6. ITER is designed to operate with $400 \mathrm{~s}$ pulses, about 100 energy confinement times. But in all of these, the current is driven at least in part Ohmically.

Recently Luce [51] wrote a review article showing the advances in achieving steady state behavior. At lower power, some tokamaks with superconducting toroidal field coils have run for very long times. The question is whether this can be extended to more powerful tokamaks. Another problem he sees is that the power required to drive the current (Watts per Amp) might be too high. However Luce envisions only pure fusion. If fusion breeding is the goal, where the fusion reactor produces ten times the neutron power in ${ }^{233} \mathrm{U}$ fuel, a bit more power to drive the current is not necessarily such a big deal.

The second crucial plasma physics goal to achieve in the the scientific prototype would be to eliminate or greatly reduce disruptions. Where a disruption in the scientific prototype would release only a small fraction of the energy released in a major disruption in ITER, it could be an ideal vehicle for his study. To achieve these twin plasma physics goals will take every bit of expertise in the American MFE effort, as well as whatever help we can get from the rest of the world. As previously stated, this is no cake walk, but the author believes it is achievable.

The scientific prototype will be a prodigious source of alpha particles even if not enough to dominate the heating. Hence it could also be a laboratory for testing ideas of alpha channeling [46, 47], at least the basic principles even if there is not enough alpha particle power to heat the plasma very much.

While proposing this in the context of fusion breeding [5-10], where the blanket would also breed ${ }^{233} \mathrm{U}$; it is also a viable concept for pure fusion, where the blanket would only have to breed tritium [50]. Since Q $\sim 1$, the Quixotic attempt to do a small scale ignition experiment would be abandoned. Let ITER and NIF handle the burning plasma and ignition issues. The American MFE effort has proposed many of such burning plasma experiments, CIT, BPX, IGNITOR, FIRE...,. Would we have been better off proposing the scientific prototype instead? We could hardly have been worse off. None of these burning plasma experiments sold, and the United States has had no large (i.e. the size of TFTR, JT-60 and JET) tokamak experiment for more than 15 years now.

While the scientific prototype would not be a burning plasma, it still would produce alphas, and unlike ITER, would do it on a steady state, or at least a high duty cycle basis. Hence it could also investigate extraction of the alpha energy on a small, but steady state basis.

The scientific prototype cannot be exactly like TFTR because its major radius is only $2.6 \mathrm{~m}$, and the center is
Table 2 Summary of parameters for JT-60, the scientific prototype, ITER and Large ITER

\begin{tabular}{lllll}
\hline Parameter & JT-60 & Sci. Prot. & ITER & L. ITER \\
\hline $\mathrm{B}$ & 4.2 & 5.1 & 5.3 & 5.7 \\
$\mathrm{R}$ & 3.4 & 4 & 6.2 & 8 \\
$\mathrm{a}$ & 1 & 1.3 & 1.7 & 2.4 \\
$\mathrm{k}$ & 1.4 & 1 & 1.7 & 1.8 \\
$\mathrm{q}(\mathrm{a})$ & 3.7 & 3 & 3.5 & 3 \\
$\mathrm{I}$ & 2.2 & 2.3 & 15 & 21 \\
$\mathrm{n}_{\mathrm{o}}(\mathrm{G})$ & 0.7 & 1.1 & 2.4 & 1.7 \\
$\mathrm{n}_{\mathrm{o}}(\beta)$ & 0.5 & 1.35 & 3.9 & 4.1 \\
$\mathrm{P}_{\mathrm{c}}(\mathrm{n})$ & & 55 & 1500 & 4000 \\
$\mathrm{P}_{\mathrm{d}}(\mathrm{n})$ & & & 500 & 1600 \\
$\mathrm{E}($ tor $)$ & 800 & 1000 & 6500 & 20,000 \\
$\mathrm{n}($ wall $)$ & & $0.25(\mathrm{c})$ & $0.5(\mathrm{~d})$ & $1(\mathrm{~d})$ \\
\hline
\end{tabular}

The eccentricity of the elliptical cross section is $\mathrm{k}$. $\mathrm{P}$ is the neutron power, a subscript of $\mathrm{c}$ means from conservative design rules, $\mathrm{d}$ means from the design. E(tor) is the stored energy of the toroidal magnetic field in megajoules, and $\mathrm{n}$ (wall) is the neutron flux on the first wall in megawatts $/ \mathrm{m}^{2}$ either as the machine is designed (d) or from conservative design rules (c)

filled with all sorts of stuff (e.g. toroidal field coils, etc.). Thus we must take a larger major radius. We take a major radius of $4 \mathrm{~m}$, like TFTR, but now leaving room for a $1.5 \mathrm{~m}$ blanket. The minor radius is $1.3 \mathrm{~m}$, so as to keep the aspect ratio as in TFTR, and would keep the circular cross section as TFTR did (although other geometries could obviously be considered). The hope is that it would produce about $40 \mathrm{MW}$ of neutron power with about a $0.25 \mathrm{MW} / \mathrm{m}^{2}$ neutron wall loading. The scientific prototype would reverse conventional wisdom, which has proposed the long list of ignition experiments. Instead of sacrificing every tokamak figure of merit for ignition, the scientific prototype would sacrifice ignition for a significant advance in every other figure of merit, i.e. steady state operation, eliminating disruption in fusion relevant regimes, extended DT operation, tritium breeding.... No other country, at this point is ahead of the United States here, we have plenty of nuclear expertise, the project seems achievable, and it is hard to see how either pure fusion or fusion breeding could advance very far without the knowledge provided by the scientific prototype.

In Table 2 are shown parameters of JT-60, the scientific prototype, ITER, and large ITER, the latter two taken from Refs. [22, 28]. The scientific prototype gives about the $55 \mathrm{MW}$ of neutron power according to conservative design rules. If one takes the rule of thumb that actual tokamaks produce about half the power of the conservative design estimates, as with TFTR and JET, then the estimate of 20-40 MW seems reasonable for the scientific prototype.

The conservative design principles show ITER and large ITER both doing better than actual predicted design values. 
However if one takes the typical estimate that predicted neutron power is about double the best achieved, large ITER gives about the design value, but ITER does especially well. It may well turn out to do somewhat better than expected. It has higher current density than either large ITER or the scientific prototype. But despite this larger current density, since q(a) is 3.5 according to Ref [22], the current could still be increased by about $15 \%$ and still remain consistent with conservative design rules, so power might be increased by $30 \%$. Note that for both ITER and Large ITER, the Greenwald density is considerably less than the beta optimized density, meaning that the ion temperature has to be considerably more than 15 ( 22 for the former, 36 for the latter), see Ref. [8] for a more complete discussion of the case where the density is Greenwald limited rather than beta limited. In any case, when quoting power levels expected for ITER and large ITER, we stick to those calculated by the designers, $500 \mathrm{MW}$ and $1.5 \mathrm{GW}$.

Several alternate American MFE proposals seem to be in the works and under serious discussion. We seems to be on the threshold of proposing a large stellarator effort, but this a bad idea. Two large American stellarator projects have already been canceled. We are hopelessly behind the Germans and Japanese in this effort and have no prospect of surpassing them. Better to let them run with the ball and support their stellarator projects, if they would support the scientific prototype. Another idea attracting interest is a larger spherical tokamak experiment. This is if anything a worse idea. Later, this paper will argue against such a proposal, as well as several other alternative concepts.

\section{Stellarators}

Our discussion of stellarators and other fusion devices, will be very brief, and will mostly make the case that none are viable alternatives to tokamaks at this time. Also this section, and subsequent sections on MFE, will site many fewer references. Information given here, which is not specifically cited, can generally be confirmed by doing a Google search of the device and going to the appropriate web site; using the information directly on the web site, as well as various articles and reports linked to it.

Despite this negative introduction, this author has no reason to think stellarators cannot ultimately work, they just have not so far. If they could work, they would have real advantages. The rotational transform is produced by external coils, so there is no plasma current. Current is one of the two causes of MHD instabilities, pressure gradient being the other. Hence disruption should be much less of a problem than in tokamaks, but it is worth noting that the stellarator like a tokamak, also stores a tremendous amount of energy.

Counterbalancing these advantages, is the fact that a stellarator is an inherently three dimensional configuration,

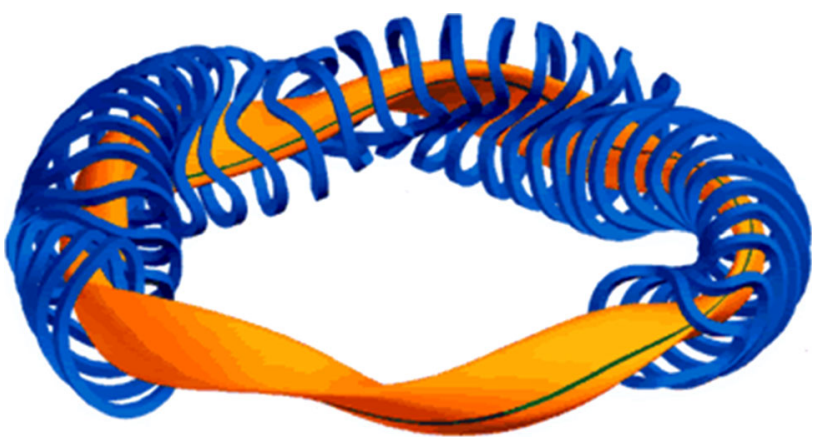

Fig. 8 An artist's conception of the plasma configuration and some of the magnetic field coils of the Wendelstein 7-X stellarator taken from its web site (www. ipp.mgp.de). Notice the five bumps around the circumference and the complicated coil structure (Color figure online)

unlike a tokamak which is a two dimensional configuration. In my view, as a theoretical physicist of normal capability, who has trouble analyzing a complex two dimensional configuration, anyone who can analyze a complex three dimensional configuration is a physicist of rare and special talent. Not only is the problem much more difficult, the parameter space much greater. For instance Wendelstein 7-X has 5 bumps going around the major circumference. Why not 4 or 6 ? Also because of the three dimensional configuration, neoclassical losses are greater than in a tokamak. A great deal of effort in the stellarator community is dedicated to coming up with configurations, which minimize these losses. Because of its three dimensional nature and the demands of minimizing losses, the coil configurations are very complicated and must be engineered to very precise tolerances. As difficult as it may be to fit a blanket around a tokamak plasma, an it might be even more difficult in a stellarator.

So far the largest stellarator is the Large Helical Device (LHD) in Japan (http://www.lhd.nifs.ac.jp/en/). To this author's mind, its achievements are not very encouraging. It seems to run in either one of two modes, a low density, high temperature mode, or a high density, low temperature mode. It has not been able to achieve high density and high temperature so far. The LHD web site gives the triple produce as $4 \times 10^{19}$, about $1 / 40$ that of JT-60. Also the web site gives the maximum contained energy so far as $1.4 \mathrm{MJ}$, about $1 / 6$ that of JT-60.

The Germans are constructing a larger stellarator still, Wendelstein 7-X. The construction is expected to be finished in 2014, with first plasma in 2015. They hope to achieve both high temperature and high density simultaneously, and they hope to achieve a triple fusion product of $4 \times 10^{20}, 10$ times higher than LHD, but still below JT-60. A schematic of the plasma and some of the field coils is shown in Fig. 8. 


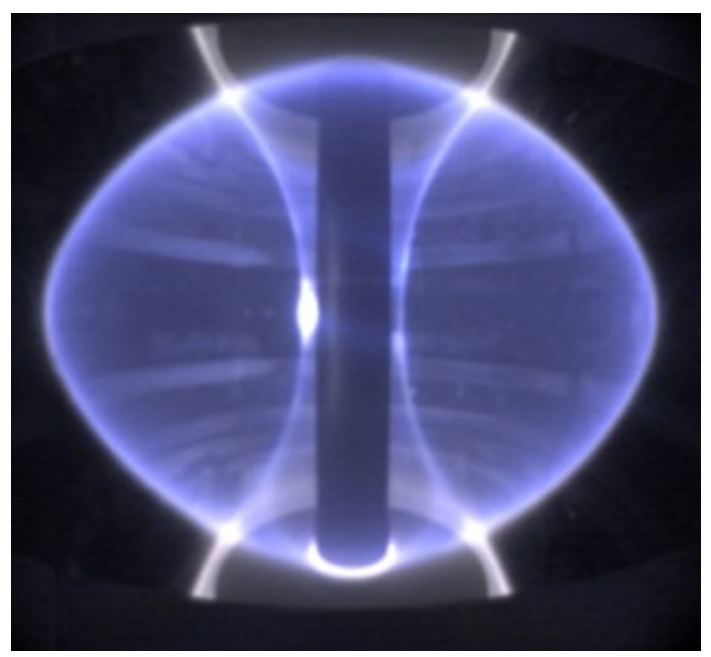

Fig. 9 A photograph of the spherical Tokamak discharge in MAST, taken from its web site (Color figure online)

The nearly infinite parameter space available for stellarators may be an opportunity, but it also poses a programmatic danger. How can we explore all of it with our very finite resources of dollars and time? LHD is a disappointment, so build Wendelstein 7-X; if that does not work, build a heliotron, if that disappoints, build a torsotron.... Where does it end?

While some in the United States argue that we start our own stellarator program, this is a bad idea. We are hopelessly behind the Germans and Japanese. Better for now to let them run with the ball and help them any way we can, at least until they can prove that a stellarator is definitely superior to tokamaks.

\section{Spherical Tokamaks (ST's)}

The spherical tokamak is like a tokamak except that it has an aspect ratio of approximately unity, so the plasma is nearly spherical is shape. Shown in Fig. 9 is an image of the ST plasma in the Culham Laboratory, MAST. It is nearly spherical with a radius of about $1.5 \mathrm{~m}$ (http://www. ccfe.ac.uk/MAST.aspx). However notice that the toroidal field coils all merge to a narrow conductor running down the center, a conductor whose radius is about $10-20 \mathrm{~cm}$ judging from Fig. 9. One of the strongest assets of the ST is that it runs at a much lower magnetic field and much higher beta than a tokamak.

The ST at PPPL is called NSTX. This author has not found information on the web sites of either MAST or NSTX, which allows one to easily discern the energy contained or the triple fusion product (unlike the JT-60 and LHD web sites, where this information is prominently displayed). However recent studies of confinement enhancement by lithium walls give this information [52].
The presence of the lithium walls in NSTX increases the confinement time from about $35 \mathrm{~ms}$ to about 70 . The energy contained is about $150 \mathrm{~kJ}$, or about $20 \mathrm{~kJ} / \mathrm{m}^{3}$, and the triple product is about $5 \times 10^{18}$. This is about where tokamaks were 30 years ago according to Fig. 1. On a more detailed plot [5], one can see that NSTX is about where ASDEX and T-10 were in about 1985, but about an order of magnitude below PLT then. Thus ST's have a long way to go before they are in the league of tokamaks, and possibly will not get there at all.

But they have a much bigger problem than their late start in the race. How will the center post handle the intense flux of $14 \mathrm{MeV}$ neutrons in a reacting plasma? According to the fourth conservative design rule, plasma facing surfaces should have a depth of about a meter and a half! Certainly the coil cannot be superconducting, so the field coils will necessarily dissipate a tremendous amount of energy. And how does one cool the center post?

There have been two proposals for much larger ST's in reacting plasmas, GA's Fusion Development Facility (FDF) (Google GA Fusion Development Facility), and the University of Texas's waste burner; their plasma parameters are similar. Here we briefly discuss the former. GA proposes the ST as a way to study a reacting plasma and study wall material in an intense neutron flux. They expect it to generate $300 \mathrm{MW}$ of neutron power in steady state, breed its own tritium, and produce a wall loading of $2 \mathrm{MW} / \mathrm{m}^{2}$ of neutron flux with a proposed upgrade to 4.4 $\mathrm{MW} / \mathrm{m}^{2}$, the minimum they say is needed for pure fusion.

The toroidal field coils will be copper and will need $500 \mathrm{MW}$ of power to run; the FDF will need its own dedicated power plant next door! While GA does not propose the FDF as a prototype for an economical reactor but rather as a neutron source; still their proposal does not exactly increase one's confidence that the ST will ever evolve into an economical reactor. This proposal is a tremendous extrapolation from the state of the art. It hopes to contain $73 \mathrm{MJ}$ of plasma energy, about a factor of 500 more than NSTX, at a plasma energy density of about $2.3 \mathrm{MJ} / \mathrm{m}^{3}$, or about a factor of 100 more than NSTX; all in single leap.

Let us compare the proposal for the FDF with the scientific prototype. Many of the goals of the two are the same, specifically running steady state in a reacting plasma, breeding its own tritium (or in the case of the scientific prototype, its own ${ }^{233} \mathrm{U}$ as well) and investigating neutron interactions with the walls. However unlike the FDF, which scales up the plasma by a gigantic jump in the unknown, the scientific prototype runs in a plasma regime scaled up only a bit from what has been accomplished. If successful it would produce a much lower wall loading $\left(0.25 \mathrm{MW} / \mathrm{m}^{2}\right.$ instead of $2 \mathrm{MW} / \mathrm{m}^{2}$, which they ultimately hope to scale 
up to $4.4 \mathrm{MW} / \mathrm{m}^{2}$ ). However as we will see, a fusion breeder probably will not require more than $1 \mathrm{MW} / \mathrm{m}^{2}$, and possibly could get by on half of that. To this author's mind the scientific prototype is not only a much safer bet, but is also a necessary way station on the path to either pure magnetic fusion or magnetic fusion breeding.

\section{Reverse Field Pinches}

Henceforth we will be even briefer in our description of alternate magnetic configurations. The reversed field pinch is a configuration, which shows interesting MHD properties. It is a torus, but the poloidal and comparable toroidal field are both pulsed and the plasma reacts to it. The system relaxes to a state, which is nearly force free, and one characteristic of this state is that the toroidal field reverses between the toroidal axis and the wall. The British first observed this in their ZETA device, and Brian Taylor in 1974 [53] came up with a particularly ingenious theory of what transpired; interest in the device persisted, and several more were built.

The largest and most actively investigated is the RFX device in Padua, although others exist in Wisconsin and Sweden. The Padua web site (www.igi.cnr.it) is a valuable source of information on what the group has accomplished, particularly their reports, the last one being in 2010, as of this writing (fall 2013). Their device has a major radius of a meter and a minor radius of about $30 \mathrm{~cm}$. Although their web site does not give direct information on $\mathrm{nT} \tau$, or contained energy, it is reasonably easy to approximate these values from the 2009 and 2010 reports. The 2009 report gives the density as about $3 \times 10^{19} \mathrm{~m}^{3}$, and the temperature as $1-1.5 \mathrm{keV}$, so the total energy contained is about $6 \mathrm{~kJ}$, about a factor of 25 below NSTX and about a factor of 300 below JT-60. The confinement time one can estimate from their reported thermal conductivity $\kappa$, in the region of a transport barrier, $\kappa \sim 10 \mathrm{~m}^{2} / \mathrm{s}$, so their confinement time $\sim \mathrm{r}^{2} / \kappa$ is about $10 \mathrm{~ms}$; giving rise to an $\mathrm{nT} \tau$ of about $3 \times 10^{17}$. In other words, by this metric, according to Fig. 1, RFP's are where tokamaks were about 35 years ago.

\section{Field Reversed Configurations and Magnetized Target Fusion}

Not to be confused with reversed field pinches, field reversed configurations (FRC's) are essentially toroidal balls of plasma without any center post. They are a theta pinch configuration except that the field lines close upon themselves. In the toroidal configuration, all fields are poloidal. There may be a toroidal field as well, and this would make it a spheromak. But in any case FRC's are free to move from place to place. In a sense, they are analogous to ball lightening, except that field reversed configurations

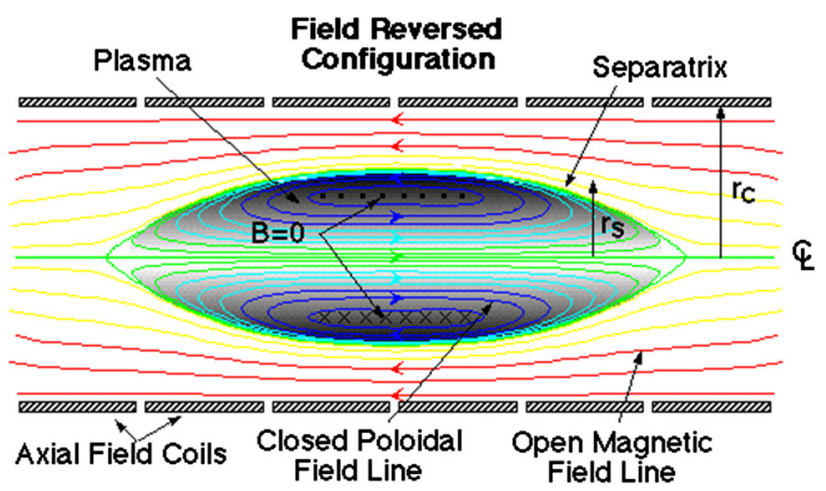

Fig. 10 A schematic of a field reversed configuration (Color figure online)

definitely exist and their properties have been measured. A schematic of a field reversed configuration, provided to Google images by the University of Washington is shown in Fig. 10.

The Los Alamos National Laboratory has been a proponent of field reversed configurations and what they call magnetized target fusion [54-56]. They produce rather dense field reversed plasmas, $\mathrm{n} \sim 2 \times 10^{22} / \mathrm{m}^{3}$ with a large magnetic field, about $5 \mathrm{~T}$, and electron and ion temperatures of about $300 \mathrm{eV}$. These plasmas only live about 10 microseconds, so $\mathrm{nT} \tau$ is about $6 \times 10^{16}$, about where tokamaks were in 1978 according to Fig. 1. They published the contained energy, which is $600 \mathrm{~J}$. Their total particle inventory is $10^{19}$ particles, so if half are $\mathrm{D}$ and half are $\mathrm{T}$, and all react they would produce about $10 \mathrm{MJ}$ of fusion energy.

To get this plasma to react, they had planned to produce it and transport it to a region where it could be compressed by an imploding metal liner. The magnetic field would be compressed by two orders of magnitude, heating the plasma to fusion temperature. So far they have not been able to do this.

Work published work on this at LANL seems to have stopped in 2005 and their web site (www.LANL.gov) makes no mention of work after this either. However there are several obvious questions. How much energy does the imploding liner use? At best their fusion energy for their published configuration is $10 \mathrm{MJ}$ assuming every DT pair fuses. In their renewal proposal, available on the LANL web site, they mention doing the compression experiment at the Shiva-Star facility at AFWL in Albuquerque. However this pulse power facility has $9 \mathrm{MJ}$, so it is hard to see how they achieve break even, much less power for the grid. Secondly can such a device be repetitively pulsed? How quickly can all the molten metal, which accumulates on each shot, be cleaned out in time to get off the next shot?

A private company, General Fusion is attempting to achieve commercial fusion power by magnetized target fusion. Very few scientific details of their work have been 
made available. They claim that they will have breakeven by 2014 and power into the grid by 2020 . Time will tell.

\section{Mirrors, Beams and Electrostatic Confinement}

We lump these together, because in the opinion of the author, they have little or no chance of ever evolving to a commercial fusion device. Consider first a mirror. At $20 \mathrm{keV}$, the optimum energy for a beta limited plasma (Fig. 4) the ion ion angular scattering cross section is about three orders of magnitude above DT fusion cross section. Hence for every ion that fuses, many, many more escape. However the energy gain from a single fusion event is so great, that the energy accounting is not as horrendous as the particle accounting. If the ion dynamics alone controlled the energy, it might be marginal. But then there are the electrons. All experience with mirrors powered by neutral beams or ICRH is that the electrons remain cool, and therefore constitute a huge energy sink for the ions. Who knows what it would take to heat them up. Quite simply, this author's opinion, backed up by many years of magnetic mirror experience, it that economical pure fusion or hybrid fusion power plants are out of reach. One large mirror machine, MFTX-B at LLNL was cancelled after the enormous field coils, along with the associated equipment had already been manufactured.

The largest and most recent effort in mirror machines directed toward fusion is the GAMMA 10 device at Tsukuba University in Japan. It is a machine at least $7 \mathrm{~m}$ in length and $0.3 \mathrm{~m}$ in radius, with all sorts of bumps and wiggles in the magnetic field in the two end sections. It is heated mostly by ion cyclotron resonance heating, and in the end cells by electron cyclotron resonance heating. Apparently there is also a capability to add neutral beam heating. A Google search 'GAMMA 10 Tsukuba University' shows little published after 2003, as does its web site (http://www.prc.tsukuba.ac.jp). As of 2002 [57], it had achieved a density of $4 \times 10^{18} \mathrm{~m}^{-1}$, an ion temperature of $4 \mathrm{keV}$, an electron temperature of $60 \mathrm{eV}$, and an energy confinement time of $10 \mathrm{~ms}$ for a triple product of $1.6 \times 10^{17} \mathrm{~m}^{-3} \mathrm{keVs}$, about 4 orders of magnitude less than what JT-60 has achieved. This is about where tokamaks were in about 1978 according to Fig. 1. The total energy confined is about $6 \mathrm{~kJ}$.

Other applications of mirror machines might be to produce an intense $14 \mathrm{MeV}$ neutron source for material studies. This is being studied at the Institute for Nuclear Physics at Novosibirsk, Russia in their gas dynamic trap [58]. The advantage here is that one might be able to get a useful neutron flux over a small but relevant area, near the high field region, with a mirror fusion device having a $\mathrm{Q}$ much less than unity.
Now consider a beam based system, D and $\mathrm{T}$ beams at optimum energy come in from opposite sides of a sphere, and meet in the center, where they fuse. The angular scattering rate, which is much greater than fusion rate would degrade the process by reducing the relative velocity between the $\mathrm{D}$ and $\mathrm{T}$. But even more important, collisions also mix up the energy at about the same rate as the mix up the angle. Thus long before this beam system could fuse, the energies would be randomized, so the deuterium and tritium would not even meet at the center any more, much less have optimum energy for fusion.

Electrostatics will not help either. Any commercial fusion reactor operating at plasma densities appropriate for fusion, will be enormous compared to the Debye length. Of course the Debye length may be large, but if so the density will be tiny, far too small for fusion. If one attempts to try to separate the electrons and ions in a dense plasma, they will just rush together and neutralize. Similarly if one attempts to impose strong electric fields from the outside, the plasma will set up its own electric field and block out the externally imposed field. I confess that I have not studied the proposal for a tandem mirror, which was based on electrostatically insulating against some end losses. However it has always seemed to me that the device would need not one, but two Maxwell demons.

Advanced Fuels, DD, D ${ }^{3} \mathrm{He}, \mathrm{p}{ }^{11} \mathrm{~B}$, etc.

The most perceptive comment I have heard regarding advanced fuels was several years ago from a well respected MFE expert at LLNL. At that time, he regarded fusion as being in something of a crisis mode also. "Don't people realize", he said "that it is fourth down, 99 yards to go, with seconds to play; and the advanced fuels advocates want to move the goal post back another kilometer!"

\section{Summary of the Status of Magnetic Fusion}

In Table 3 we plot the $\mathrm{nT} \tau$ and the confined energy of the various MFE devices we have discussed. Let us recall that it has taken decades of international effort and billions of dollars for the tokamak to get to where it is now. Is it reasonable to think that any of the other devices (with the remotely possible exception of the stellarator) can achieve what a tokamak has achieved today, in any relevant time scale, let alone produce commercial fusion power? This author's answer is no. The chart then answers another dilemma; in designing a fusion reactor, do we start with what the reactor would like and work backwards to the optimum plasma configuration, likely a field reversed configuration but without the ultimate magnetic compression? See from Fig. 10 how relatively simple it would be it put a blanket around it. Or do we start with the optimum 
Table 3 First column is the device, second is the $n T \tau$ in units of $\mathrm{m}^{-3} \mathrm{keVs}$, third is energy contained in megajoules, and the fourth column contains simple comments

\begin{tabular}{|c|c|c|c|}
\hline Device & $\mathrm{nT} \tau$ & Confined energy & Comment \\
\hline Tokamak (JT-60) & $1.6 \times 10^{21}$ & 8.6 & \\
\hline Stellarator (LHD) & $4 \times 10^{19}$ & 1.4 & $\begin{array}{l}\text { So far can achieve either High density or } \\
\text { high temperature }\end{array}$ \\
\hline ST (NSTX) & $5 \times 10^{18}$ & 0.15 & Center post likely a show stopper \\
\hline RFP (RFX Padua) & $3 \times 10^{17}$ & 0.006 & \\
\hline Mirror (GAMMA10) & $1.6 \times 10^{17}$ & 0.006 & $\begin{array}{l}\text { Non Maxwellian distribution likely a show } \\
\text { stoppe for energy production }\end{array}$ \\
\hline FRC/MTF (LANL) & $6 \times 10^{16}$ & 0.0006 & $\begin{array}{l}\text { Metal kinetic energy and need to clean up molten } \\
\text { metal between shots likely a show stopper }\end{array}$ \\
\hline
\end{tabular}

plasma and work forward to the reactor? This chart provides the answer; we start with the plasma and work forward. The magnetic fusion program has little choice but to continue to dance with the lady that it came in with.

\section{Inertial Fusion}

Inertial fusion energy (IFE) relies on the deposition of an enormous amount of energy in a tiny target so as to heat it up to fusion temperature and density, let it fuse and then blow apart. In other words, there is no confinement as in MFE. IFE relies on the fact that the target fuses before it can blow apart. There are various proposed drivers for IFE, lasers, heavy ion beams and possibly others. In any prospective IFE power plant, the energy will come out in a series of explosions repeated at some rate, rather like an internal combustion engine in a car. Thus a figure of merit for any such power plant will be how quickly the debris can be swept away so the next shot can be fired. The less mass there is in the target, the better; and also the more standoff between the driver and target, the better.

Inertial fusion has a number of significant advantages over magnetic fusion. As we have seen, MFE requires the concentration of enormous energy (gigajoules) in very small volume, an obvious potential danger. This is not the case with IFE. Consider NIF, the laser is $1 \%$ efficient and delivers $3 \mathrm{MJ}$ at $1.06 \mu \mathrm{m}$ wavelength and 1-2 MJ at the third harmonic. Thus for each shot, $300 \mathrm{MJ}$ must be stored. However NIF has 192 individual lasers, so each one must store just over $1 \mathrm{MJ}$, and all of the units are independent and separate. If one of them blows up, there is very little potential for damage; and this is for NIF, a rather inefficient laser. Any laser for a power plant must be much more efficient, so there will be even less potential for wide scale damage from an accident in one of its power supplies. IFE is inherently safer than MFE.

Secondly, since the target fuses and blows apart, IFE does not have to worry about confining a burning plasma.
At this point, the MFE program has no experience with burning plasma, and can only speculate on the problems of confining alphas, overheating the plasma, alpha-generated instabilities and the like.

Thirdly, there has been scuttlebutt around the community that the concept has been confirmed by classified experiments underground called Halite Centurion, but who knows if this is really so or what the details are [59].

Fourth, the blanket size of a tokamak is determined by the geometry of the plasma; there is little if any flexibility. The inertial fusion target fuses at the center of a spherical target chamber (about $10 \mathrm{~m}$ radius at LLNL). However there is at least some flexibility to make the target chamber larger or smaller if conditions require.

Finally, unlike tokamaks, there does not seem to be any limiting features like conservative design rules which has yet appeared in the theory of inertial fusion. And of course bombs do work.

\section{Lasers}

\section{The Development of Laser Fusion; Indirect Drive}

As with tokamaks, laser fusion has been under development internationally for decades at a cost of many billions of dollars. There are large programs in the United States, France, Japan and other places. The main program in the United States, is at the Lawrence Livermore National Laboratory (LLNL). The other American programs are at University of Rochester Laboratory for Laser Energetics (URLLE), and at the Naval Research Laboratory (NRL).

Almost as soon as lasers were invented, scientists thought of them as drivers for inertial fusion. Initially the thought was to simply deposit the energy in a target, heat it to fusion temperature and let it fuse. However, the laser energy needed was enormous, many, many megajoules. A significant theoretical breakthrough came when Nuckolls showed that by ablatively compressing the target, the laser energy could be enormously reduced, perhaps to as low as $10 \mathrm{~kJ}$ or less [60]. 
Ablative compression means is that the laser deposits its energy in the outer region of the target, which heats up, ablates away, and the inverse rocket force compresses the remainder of the target to fusion conditions.

To achieve this requires a spherical implosion, so maintaining the spherical symmetry is of utmost importance. This means that one must find a way to minimize the effect of the Raleigh Taylor instability, which is unavoidable, since ablative compression necessarily means the acceleration of a heavy fluid by a light one. An enormous effort has been made here, and the community generally agrees that the outward ablative flow has a strong stabilizing effect, although just how strong is still under study. In any case, by taking advantage of the flexibility one has in designing the laser pulse, one can exert a measure of control over the flow so as to minimize the effect of the instability.

While Nuckoll's idea is still the main one being pursued today, as we will see, his original estimate of necessary laser energy was nothing if not optimistic. In the pursuit of laser fusion, LLNL embarked on major program developing a series of larger and larger lasers, Argus, Shiva, Nova, Beamlet,and finally NIF. All of these are Nd glass lasers with a wavelength of $1.06 \mu \mathrm{m}$. However at such long wavelengths, laser plasma instabilities become a major worry. Accordingly, LLNL has developed frequency multiplication techniques to operate at third harmonic, about $1 / 3 \mu \mathrm{m}$ wavelength. LLNL now routinely operates with pulses in excess of a megajoule at third harmonic. URLLE has also taken this approach with their OMEGA laser $(30 \mathrm{~kJ})$. NRL has taken a different approach, using a $\mathrm{KrF}$ laser at a wavelength of $0.248 \mu \mathrm{m}$ with its NIKE $(3-5 \mathrm{~kJ})$ and Electra lasers.

In terms of economics and timelines, the experience of NIF has not been so different from the experience of ITER, but at least NIF is now operational. It was approved in 1995, to be finished in 2002 at a cost of $\$ 1.1 B$. It was finished in 2009 at a cost of $\$ 3.5 \mathrm{~B}$. It is also important to note that the sponsor for NIF is not fusion energy, but nuclear weapon stockpile stewardship. Accordingly the sponsor has little interest in such things important to energy as laser efficiency or rep rate. More important, the sponsor interest is only in a particular type of implosion driven by X-rays. This necessitated a particular type of target configuration called indirect drive. The target was placed inside a high $\mathrm{Z}$ enclosure called a hohlraum, the laser was focused on the inner walls of the hohlraum which heated to a temperature which produced black body X-rays at a temperature of $250-300 \mathrm{eV}$. These X-rays, not the laser, drive the target. The hohlraum is filled with helium gas to provide a back pressure to keep the heated walls from expanding into the target.

Once the laser light enters the hohlraum, the helium is ionized, so the light must traverse a large, likely uniform plasma. Laser plasmas instabilities are a vitally important issue here, and LLNL has dedicated great resources to their analysis [61]. They believe they have things under control.

Furthermore, the sponsor, which paid for NIF, has many other uses for it besides fusion, and wants the facility for its own purposes more and more. A view of NIF, emphasizing the different important scale, kilometers down to millimeters is shown in Fig. 11.

In preparation for the ignition campaign, LLNL had done an enormous amount of work. In a major article [62], cited over 1500 times, Lindl and his coworkers have documented the theoretical basis for the project. A tremendous amount of work, by a large number of people went into the preparation of this article; it is most likely beyond the capability of any single person to absorb all of it (certainly well beyond the capability of this author). However the article it unambiguous in one respect, it predicts a $Q$ (fusion energy over laser energy) of about 10 over a broad region of parameter space. As NIF was further delayed, LLNL's theoretical efforts continued. In another paper summarizing 6 years of additional effort [63], their predicted gain remained 10 .

It is now well known that nature did not cooperate. Their gains are just over $10^{-3}$. Among other things, they observe about $10-15 \%$ of the laser light back scattered out of the hohlraum by stimulated Raman scatter. There may be more scattered light remaining in the hohlraum. While this might not seem like a killer, one characteristic of stimulated Raman scatter in the nonlinear regime is that it generates copious energetic electrons, whose total energy is about half that of the scattered light. Hence they could have as much as $100 \mathrm{~kJ}$ of energetic electrons, some with energies likely in excess of $100 \mathrm{keV}$ bouncing around the hohlraum in a manner, which is likely nearly impossible to calculate today. Furthermore, in all likelihood there are 1-5 Megagauss magnetic fields (i.e. a $100 \mathrm{keV}$ electron has a 1-5 $\mu \mathrm{m}$ Larmor radius) in the hohlraum driven by non parallel density and temperature gradients. These fields almost certainly have a complicated special and temporal structure. Who knows what will be the influence of $100 \mathrm{~kJ}$ of energetic electrons bouncing around the hohlraum will be.

In a recent article in Physics of Plasmas LLNL [25] has summarized their progress on the National Ignition Campaign (NIC) to date. A schematic of their experiment, taken from the available web version of Ref [25] is shown in Fig. 12. Of many of the key parameters for ignition, for instance or (density times radius) and implosion velocity, they are within $90 \%$ of what is needed. However these achievements were not obtained simultaneously on the same shot. In fact some of the necessary parameters were quite far from what is required. Their best hot spot pressure achieved was two to three times below their code 

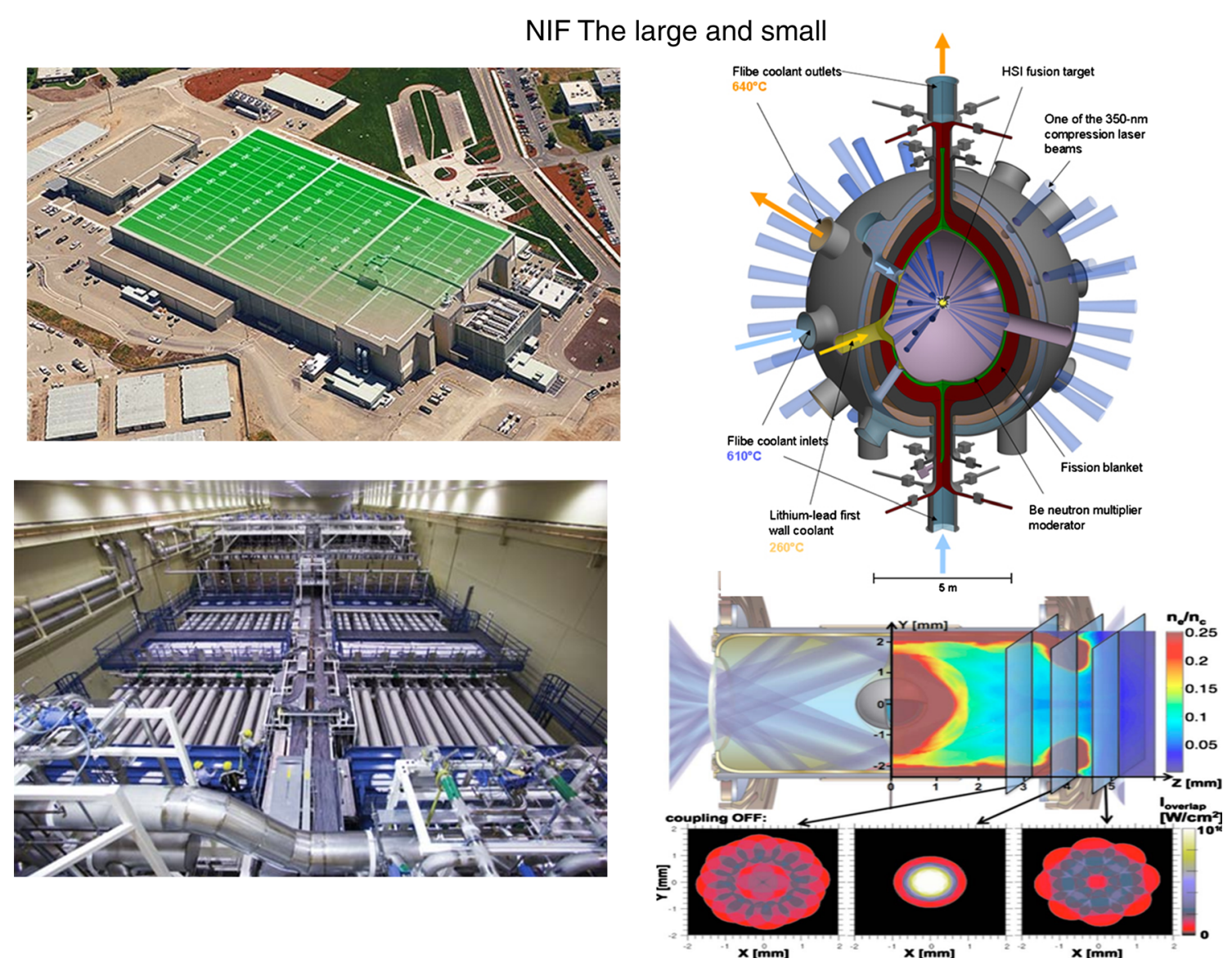

Fig. 11 Various photos of NIF, taken from the LLNL web site, emphasizing the tremendous range in size, from about half a kilometer for the overall facility, to the $100 \mathrm{~m}$ laser bays, to the $10 \mathrm{~m}$ target chamber, to the $1 \mathrm{~cm}$ hohlraum, to the $1 \mathrm{~mm}$ target (Color figure online)

predictions. Their target mass was about $200 \mu \mathrm{g}$ of DT. LLNL had estimated that with about $0.1 \mu \mathrm{g}$ of ablator mixing with the target, they would be okay. However their measurements indicated that about 3-4 $\mu \mathrm{g}$ of ablator were mixing with the target, 30-40 times the acceptable level! For the most part they seem to think that hydro instabilities and lack of necessary symmetry were their biggest problem. To this author's mind, it is surprising that they paid so little attention to laser plasma instabilities and energetic electrons, a subject they discussed in many APS meetings.

Finally it is important to note that despite their problems, LLNL seems to be making some progress. In their 2013 Physics of Plasmas (submitted in March 2013) paper, the maximum neutron production they quoted nearly $10^{15}$. However on a shot on Sept 28, 2013, they did achieve $5 \times 10^{15}$ neutrons [26]. But they still have a very long way to go. They have not achieved that much more gain than what URLLE had achieved in a direct drive (the laser illuminates the target instead of a hohlraum) experiment with only $30 \mathrm{~kJ}$ of laser energy [64].

The fact remains that NIF was a multi billion dollar investment which missed the calculated gain by over three orders of magnitude as of January 2014. Despite the natural advantages of inertial over magnetic fusion pointed out earlier, magnetic fusion is still way ahead of inertial fusion in neutrons produced and gain achieved. MFE certainly has not had a disaster of the scale of missing its calculated a gain by over three orders of magnitude in an expensive machine. It serves nobody's interest to deny this or to attempt to sweep it under the rug. Inertial fusion's credibility today is not exactly riding high. Surely congress will never approve another multi billion (or even multi million) dollar inertial fusion machine until NIF achieves some measure of success. To be blind to this is simply to live in a dream world. As regards inertial fusion, NIF is what we've got, it is all we've got, and it is all we will have for quite some time. The only reasonable goal now is to get it to work, assuming congress does not get annoyed and pull the plug. Hopefully this will not happen. The rest of this section discusses some of the ways NIF might be made to work, and the potential for inertial fusion energy, assuming that NIF and inertial fusion can get beyond their current difficulties. 
Fig. 12 A schematic of the NIF target in the hohlraum with the different arrays of laser beams fired in, the schematic of the target itself, and the laser pulse as a function of time (dotted curve is the $\mathrm{X}$-ray) pulse taken from Ref. [25] (Color figure online)

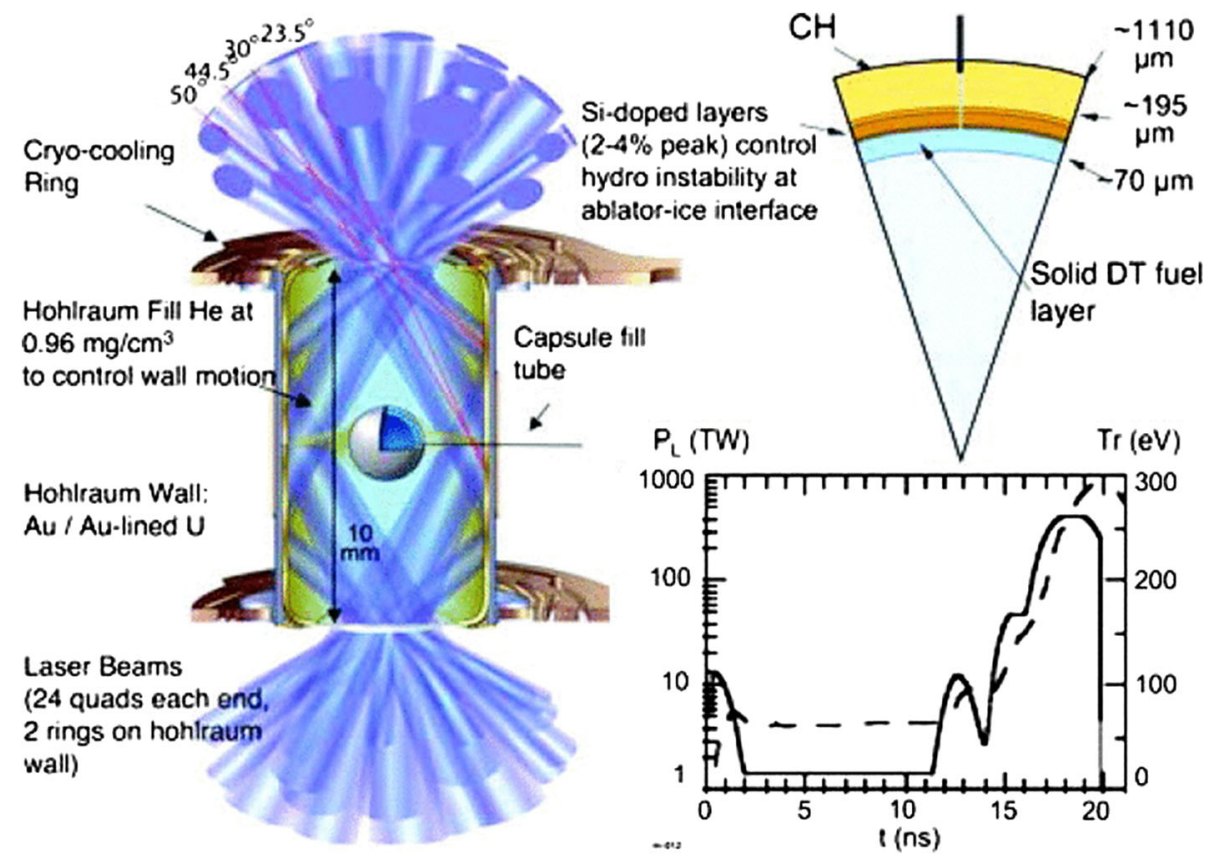

\section{Direct Drive}

An obvious alternative to indirect drive is direct drive, where the laser, spherically symmetrically, illuminates the target rather than a hohlraum wall. During the 15 or so years that the NRL program was an independently funded congressionally mandated program, it focused only on energy and only on direct drive. The URLLE program focused on indirect drive in support of LLNL and NIF, but also on direct drive. There are certain advantages to direct drive, both regarding the physics, and also regarding its applicability as an energy source.

Let us first concentrate on the physics. As the laser illuminates the target and does not go through an intermediate stage of conversion of light to X-rays in the hohlraum, there is one less channel for energy loss by the laser light. Accordingly, there are fewer calculations one must make to evaluate the target performance. Then there is the fact that the laser has to propagate through much less plasma to reach the target, so there is less opportunity for laser plasma instabilities, although they are still an important consideration. As long as spherical symmetry is maintained, the density and temperature gradients are parallel, so there should not be any magnetic field generation, further simplifying the physics and the analysis.

However for direct drive to work, the transverse spatial profile of the laser must be very uniform in order not to induce azimuthal structure in the target, which can serve as seed for the Rayleigh-Taylor instability. LLNL, URLLE and NRL have all come up with optical means of generating uniform laser beams. Common to all is a requirement of laser bandwidth. At this point $\mathrm{KrF}$ lasers like NRL's NIKE have the potential for about $3 \mathrm{THz}$ of bandwidth, URLLE's OMEGA, about $1 \mathrm{THz}$, and NIF, about $500 \mathrm{GHz}$ early in the pulse (when the amplitude is lower) and less later on. These bandwidths also have the advantage of having a stabilizing effect on laser plasma instabilities.

But the main advantage of direct drive is that the calculated gains are much higher for direct drive than for indirect. Recall that LLNL's own calculations for indirect drive show a gain of only about 10 . The calculated gains for direct drive are much greater. Shown in Fig. 13 are calculated gains as a function of laser energy for a series of different sorts of laser pulses. These curves were calculated assuming a $\mathrm{KrF}$ laser. Its shorter wavelength gives rise to an advantage in ablation pressure and threshold for laser plasma instabilities. However a $\mathrm{KrF}$ laser has an additional advantage over a frequency tripled $\mathrm{Nd}$ glass laser. It has a capability to perform what NRL calls zooming. That is part way through the laser pulse, even at maximum laser power, its focal properties can be changed, one or more times, in nanoseconds, so that as the target shrinks, the focal spot size does as well. Hence less laser light is lost in going around the shrinking target.

The lower curve in Fig. 13 is NRL's original calculation [65] of what is called central ignition. The same laser pulse is used to both compress the inner part of the target and to heat it. Most of the compression is done at low adiabat. When the target is sufficiently compressed, it is heated to fusion temperature. The inner part begins to fuse, the alpha particles are locally deposited and heat the nearer parts, and 


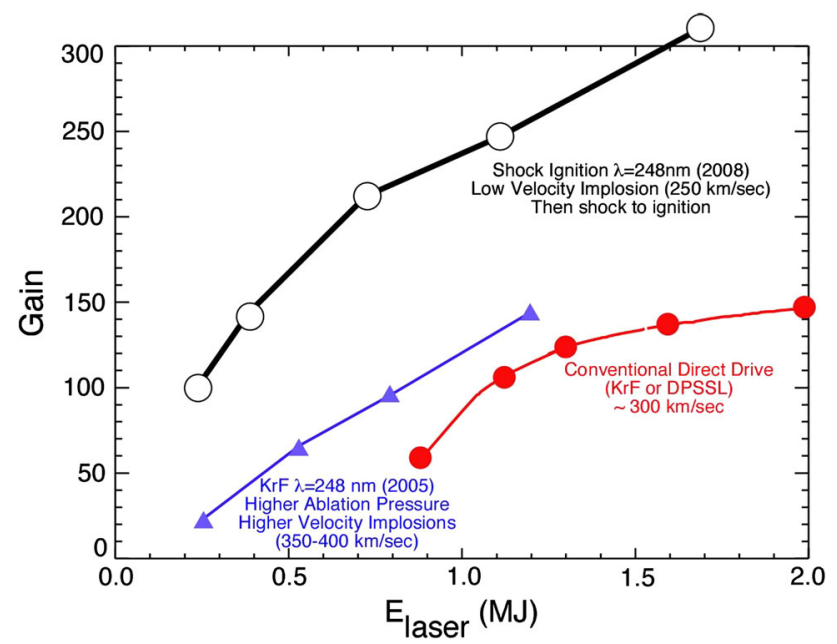

Fig. 13 NRL calculations of laser gain versus energy for a KrF laser with zooming. Black (top), Shock fast ignition; blue (middle), higher implosion velocity, higher ablation pressure drives as proposed for the Fusion Test Facility; and red (bottom), conventional central ignition (Color figure online)

a propagating burn wave propagates outward consuming the fuel.

The middle curve was an effort made by NRL to investigate whether gain could be achieved at lower laser energy. The idea was to take advantage of the higher ablation pressure available from a quarter micron $\mathrm{KrF}$ laser so as to accelerate the target to a higher inward velocity. NRL found that significant gains could be achieved in this manner. Accordingly it proposed the Fusion Test Facility (FTF, not to be confused with GA's proposed FDF) as a means of investigating fusion neutron production with the lowest possible energy laser [66, 67].

In 2007, Riccardo Betti, of URLLE proposed a new scheme, shock ignition [68]. The idea here is to use a more structured laser pulse, so that the compression is done at the early part of the pulse, and when the center is compressed to sufficient density, while remaining cool, a second intense laser pulse is fired in. This sends in a shock wave, which collides with the reflected shock form the initial pulse and heats the plasma to fusion temperature. In this case, the original compression is at lower inward velocity. NRL did its own calculations on shock ignition [69] in 2010 and confirmed their potential for a $\mathrm{KrF}$ laser with zooming capability in a series of one and two dimensional fluid simulations. Shock ignition is now NRL's standard approach to laser fusion.

It is worth noting also that the URLLE has actually done implosion experiments with cryogenic DT targets [64]. While with their $30 \mathrm{~kJ}$ laser they could not achieve ignition they did get decent neutron production and central ion heating. Shown in Fig. 14, taken from the available web version of [64] shows the neutron production and central
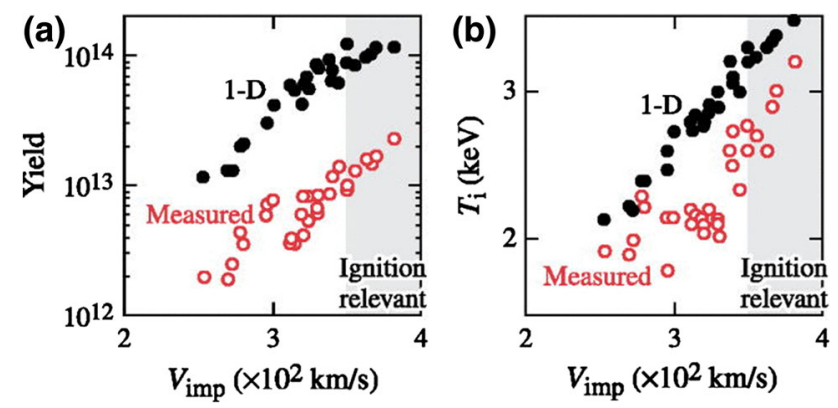

Fig. 14 Measurements of neutron yield and ion temperature in direct drive powered by the OMEGA $30 \mathrm{~kJ}$ laser at URLLE taken rom Ref [64] (Color figure online)

ion temperature as a function of implosion velocity. The maximum neutron production is about $2 \times 10^{13}$, or about $45 \mathrm{~J}$. Since the maximum energy of OMEGA is $30 \mathrm{~kJ}$, this corresponds to a $\mathrm{Q}$ of at least $1.5 \times 10^{-3}$, not that much less that what NIF has achieved with indirect drive with over a megajoule of laser energy.

There are also powerful economic and scientific arguments for direct drive laser fusion. For instance let's stipulate that an indirect drive system produces $100 \mathrm{MJ}$ of fusion energy in a single shot. However when converting to electricity, this is about $33 \mathrm{MJ}$ of electricity, or $9 \mathrm{~kW} \mathrm{~h}$; worth about a dollar. While today's hohlraums cost many thousands of dollars each, mass production would undoubtedly bring down the cost, but certainly not to zero. After all these hohlraums are precisely engineered and contain such expensive materials as gold and/or uranium. Between shots, not only would the debris of the target have to be swept away, but also the debris of the hohlraum. Furthermore, the target would be dropped into the target chamber from the top, and when it gets to the center, the laser would be fired at it. Direct drive only has to get the target there, indirect drive has to both get it there and orient it properly as well. To summarize, there seem to be both physics and economical reasons indicating that direct drive has an advantage over indirect drive.

\section{NRL's HAPL Program}

The High Average Laser Power program (HAPL) was a multi year, multi institution program managed at NRL. It existed from 1999 until 2008, when it became a casualty of the financial collapse. Its accomplishments have been documented on the ARIES web site (aries.ucsd.edu/ HAPL). The program goal was to investigate every aspect of laser fusion with the goal of developing all of the science and engineering necessary to make it a reality. For instance its namesake goal was to develop lasers capable of high average power and efficiency, which are suitable as drivers for laser fusion. To bring this about, HAPL supported 2 
laser projects, the Electra laser at NRL, and Mercury laser at LLNL. The former is a $\mathrm{KrF}$ laser, with an energy of $300-700 \mathrm{~J}$ per pulse and runs at a rep rate of $2-5 \mathrm{~Hz}$. The latter is a frequency tripled diode pumped solid state laser, with an energy of $50 \mathrm{~J}$ per pulse and runs at about $10 \mathrm{~Hz}$.

However lasers were hardly the only aspect investigated in HAPL. It involved some 30 institutions investigating such things as first wall, final optics, the chamber, the target manufacture, the target positioning, the target tracking.... The program was an integrated program with the goal of achieving economical and practical laser fusion. No single goal was regarded as paramount. In fact the mantra of the project was "You cannot solve your problem if you make the next guy's problem impossible".

Hence the philosophy underlying HAPL was much like that of the Scientific Prototype, proposed earlier in this paper. There the goal would be to solve very problem except the burning plasma; that would be left to ITER. However an obvious difference is the HAPL was a reasonably well funded project with many participants; the scientific prototype, at least as of now, has zero dollars and a single proponent (just me). The motivation of HAPL and the Scientific Prototype is just the opposite to the motivation of the various proposals for small burning plasma tokamaks (FIRE, BPX...), which, if successful, would solve the burning plasma problem, but would make everybody else's problem impossible (in other words, there was no clear path from say FIRE, which would only last 3000 shots to an economical fusion machine). HAPL's and the Scientific Prototype's goal is to advance the field on as broad a front as possible.

The HAPL program had made steady progress during its brief lifetime, along a very broad front, and believed that there were no show stoppers.

\section{What Next for NIF and Laser Fusion?}

At this point the next step for NIF is uncertain. Some are in favor of attempting other types of indirect drive experiments in the hopes that one will work. But these would have to increase the measured gain by over 3 orders of magnitude in order to achieve what LLNL expected in 2004 and 2010.

Others favor switching to a several year science based program to examine more of the physics of indirect drive in the hopes that a new pathway will become apparent.

Then there is the possibility of converting NIF to what is called polar direct drive. This would use the existing target chamber and existing beam lines to directly illuminate a target. However the illumination would not be uniform over $4 \pi$ solid angle, but most of the illumination would be at the poles. Thus with polar direct drive, laser fusion would be giving up spherical symmetry, one of its most important advantages. Target designs and the like would be optimized to make the implosion as symmetric as possible. But there are other problems as well. As the illumination is non uniform, some azimuthal angles will have greater illumination, and these would be subject more to laser plasma instabilities than would be the case for uniform illumination. This author worries that polar direct drive could be a large time and dollar sink spent on a non optimum configuration.

URLLE has proposed polar direct drive experiments on NIF. Apparently they believe that NIF can be reengineered to have sufficient bandwidth and other attributes for the process to work. LLNL seems reluctant to go this route. This is apparent in the dueling cost estimates to refit the laser for polar direct drive [70]. LLNL's Edward Moses estimates the cost at $\$ 200 \mathrm{M}$ or more, while Riccardo Betti, an expert from URLLE estimates a cost of $\$ 40-50 \mathrm{M}$.

Steven Bodner [71] has a contrasting proposal: that NIF should be scrapped and replaced by two laser development programs, one on KrF lasers and one on DPSSL's. Each program would attempt to develop a $100 \mathrm{~kJ}$ laser, with the characteristics needed for direct drive fusion, and which would have a rep rate of $5 \mathrm{~Hz}$. These would be used to test as much as they could on planar, spherical and conical targets, and if these tests were successful, build a megajoule class rep rated laser to power a fusion test facility. In other words, tell our sponsors, sorry, we made a big mistake with NIF, but give us a few hundred million more to develop two lasers, and then give us a few billion more for a perfect megajoule class laser, all the while dismantling the imperfect one we have right now.

Bodner does mention another possibility, but then seems to dismiss it. In his letter to the NAS, he states "Unofficial and rumored estimates from LLNL say that the conversion to symmetric illumination for direct drive would cost over $\$ 300 \mathrm{M}$ and take at least 2 years. Since the paying customer is the weapons program, it won't happen". But if these estimates are correct, why won't it happen? It is certainly the fastest and cheapest way to achieve megajoule class direct drive experiments.

The weapons program definitely would not be happy, especially where they paid for it; but they are not the only constituency. The House Appropriations Committee is a rather important and powerful group as well, and they should not be ignored. As stated in the Introduction, they do not think the weapons related work is worth the expenditure, only ignition is.

As Bodner points out, NIF is hardly ideal for direct drive experiments, because of its limited bandwidth. But how much does this matter? If URLLE believes it can get NIF beams satisfactory for polar direct drive experiments, then they surely must believe that these modified beams would also 
work at least as well in a spherically symmetric configuration, a configuration certainly more likely to achieve success.

Also direct drive gain calculations show impressive gains at half a megajoule laser energy. NIF has nearly 4 times this. Hence there is a very large margin for error both regarding the laser energy and the gain calculations. Let's say NIF does a symmetric direct drive experiment and gets a gain of 'only' 10 . Wouldn't this be a tremendous accomplishment? It might be just 2 or 3 years away. Might it not encourage Congress to build the ideal laser or lasers Bodner suggests?

\section{Laser Fusion for Breeding}

With NIF spending billions, but failing by 3 orders of magnitude in its prediction of gain, the question of pure fusion or fusion breeding is hardly laser fusion's main concern at this time. In fact officially, pure fusion or fusion breeding is not a concern at all. There is no American laser fusion energy program. NIF is sponsored for nuclear stockpile sponsorship; other US laser fusion programs are now either in support of NIF, or else are tiny by comparison. However even a brief perusal of the LLNL web site makes clear that NIF for energy is very much on the minds of the Lawrence Livermore National Laboratory. In fact LLNL invited Thomas Friedman to visit NIF just as all 192 lasers were simultaneously operating. Edward Moses, the project leader guided him and Friedman interviewed him in his op ed [72]. It was all about energy; there was not a word about stockpile stewardship. No, LLNL has energy very much on its mind despite its sponsor.

Even if NRL's optimistic theoretical results are born out in experiments, there could be a problem as regards pure fusion. Let us take the most optimistic result, a gain of 250 with a $1 \mathrm{MJ} \mathrm{KrF}$ laser, assumed to be $7 \%$ efficient [69]. Take a rep rate of $6 \mathrm{~Hz}$ so that the same $1.5 \mathrm{GHz}$ of fusion energy is produced as for our assumptions for large ITER and NIF. This then produces $500 \mathrm{MW}$ of electricity. But the laser needs $14 \mathrm{MJ}$ for each shot, so the 6 shots per second would need about $100 \mathrm{MW}$ of the electrical energy produced, leaving about $400 \mathrm{MW}$ for the grid. This is better than ITER or NIF discussed in the Introduction; it may or may not be an economical power producer. Judging from the size of NIF and its $\$ 3.5 \mathrm{~B}$ price tag, a laser with the same energy per shot, but much greater average power is unlikely to be smaller or cheaper. But $\$ 3.5 \mathrm{~B}$ is a high price for one major part of a $400 \mathrm{MW}$ power plant. So there still could well be a real need for the enhancement in gain fusion breeding could provide, even if NRL's optimistic calculations prove to be valid.

But then what if the calculations prove optimistic? If there is one thing to learn from the experience of NIF, it is that there are large gaps in our knowledge of laser fusion, certainly for indirect drive, perhaps even for direct drive. If the gain and efficiency are 'only' 100 and $3 \%$, the example given in the introduction, then pure fusion becomes virtually impossible. However the order of magnitude increase in $\mathrm{Q}$ from breeding would make all the difference. Using laser fusion for breeding instead of pure fusion gives a much larger margin for error in case the calculations prove to be optimistic. It is certainly a much more conservative approach.

\section{Sandia's Z Machine}

We mention Sandia's Z before heavy ion fusion because $\mathrm{Z}$ does exist, heavy ion accelerators so far exist only on paper. The $\mathrm{Z}$ machine is likely the largest pulse power facility in the world. Like NIF, it is sponsored for weapons research. The lab, on its web site does mention fusion (w.sandia.gov/z-machine/), but does not give fusion nearly the emphasis that LLNL gives NIF on its. The $\mathrm{Z}$ machine is an intense X-ray generator. Inside a hohlraum about the size of a spool of thread are many thin tungsten wires stretched axially near the edge, or in an axially nested array. The machine is discharged through these wires, more than $2 \times 10^{7}$ amps. These wires vaporize and produce a tungsten plasma which both generates $\mathrm{X}$-rays and implode toward the center producing still more X-rays. Typically they produce nearly $3 \mathrm{MJ}$ of X-rays, certainly more than NIF has generated. The machine typically gets off about one shot per day. A great advantage of $\mathrm{Z}$ over lasers is its relative simplicity and low cost as compared to say NIF.

The plan for using $\mathrm{Z}$ as a fusion device, the idea is basically like indirect drive on NIF. There seems to be no analog for direct drive. While $\mathrm{Z}$ does produce copious $\mathrm{X}$-rays, it does have some limitations as a fusion device. First of all, lasers have the capability of tailoring the pulse so as to meet requirements. For instance in URLLE's direct drive spherical implosion experiments [64], they use precisely structured pulses with several prepulses (which they call pickets) on the leading edge; also Fig. 12 shows the precisely structured pulses that NIF uses. Sandia on its web site does not seem to have mentioned structuring the pulse in any way. Secondly, lasers have standoff and $\mathrm{Z}$ does not, so replacing targets after each shot is a challenge. Sandia has given some attention to this, principally by envisioning a power plant as having as many replicated $\mathrm{Z}$ machines as necessary, so as to provide time between shots to replace the target and wires. It may be that $\mathrm{Z}$ will ultimately evolve toward a viable fusion device, but it seems to be far behind lasers right now.

\section{Heavy Ion Fusion}

As discussed in the Introduction, the proponents of heavy ion fusion (HIF) have every confidence that they can rather 
quickly produce economical fusion. The advantage of an ion beam over a laser is its efficiency. Counterbalancing this advantage is the fact that spherical direct illumination is not possible. Also they are starting out with very little equipment. The main effort seems to be in Russia under Boris Sharkov [73]. Also Germany is a main partner in constructing an international heavy ion accelerator called FAIR (http://www.fair-center.eu/public.html), but it appears to have nowhere the parameters needed for fusion, and the accelerator does have many other customers, fusion being a minor one, if in fact it is a customer at all. In the United States, the main effort is at the Lawrence Berkeley Laboratory. However the resources for accelerator or target experiments are so meager that most of their work is in numerical simulations. In fact their HIF lab is called the virtual laboratory, both because their work is mostly simulation, and also because they are bringing several other laboratories and organizations together to hopefully work as one (http://hif.lbl.gov/VNLoverview.html).

The Russian effort proposes a $10 \mathrm{~km}$ long $100 \mathrm{GeV}$ (about $500 \mathrm{MeV}$ per nucleon) heavy ion accelerator coupled with eight storage rings, each about $1 \mathrm{~km}$ in diameter. These store and compress the heavy ion beam, which would have a total energy of about $7 \mathrm{MJ}$. This does not look inexpensive. Although it is said that standard accelerator technology is sufficient, Sharkov et al. [73] do list 5 difficult challenges the accelerator must overcome. It is not clear from Ref [73] just how much of the accelerator has actually been built.

The Russian target design is a modification of laser direct drive. A small cylindrical DT target is encased in a larger lead cylinder. The beam is deposited in the lead and the DT is compressed cylindrically; note that they are giving up on spherical compression. Also in NIF targets, mixing of fuel and ablator is a major problem. But in NIF, the ablator is about half of the target mass. How simple will it be to keep the fuel in Sharkov's target separate from the much more abundant lead? Note also that even thought the target is inherently 3 dimensional (rz for the cylinder and theta of there azimuthally dependent instabilities), their hydrodynamics codes are all either one or two dimensional.

The Berkeley target design uses indirect drive. The annular cylindrical beam deposits in a hohlraum to generate $\mathrm{X}$-rays to implode the target. However its hohlraum must certainly be thicker and heavier than a laser hohlraum since the entire ion beam must fit inside it. For either the Berkeley or Russian design, there will be much more material to be swept away between shots than for laser fusion, either direct or even indirect drive.

This author has recommended that we let the Germans and Japanese proceed with their stellarator programs, help them any way we can, but not jump in ourselves unless they prove to be definitively superior to tokamaks. The recommendation is the same for HIF. Let the Russians run with it, help them in any way we can, but not start a program ourselves unless they can prove it to be definitively superior to lasers. Right now they appear to be hopelessly behind.

\section{Nuclear Issues}

We now turn to the nuclear issues, which we discuss as briefly and simply as possible.

\section{Fusion Breeding}

In pure fusion, the $14 \mathrm{MeV}$ neutron uses only its kinetic energy to boil water, because tritium breeding is relatively undemanding of neutron economy. In fusion breeding, it does this, but also uses what we have called its potential energy to breed enough nuclear fuel to produce ten times more fission power than fusion power. For breeding, the neutron is first inserted into a neutron multiplier, for instance lithium, beryllium, lead, uranium or some other material. (Even pure fusion needs some neutron multiplication, since the reaction produces only a single neutron, so none could be lost.) Here the fast neutron produces 2-3 slower slower neutrons. One of these is used to breed tritium to keep the fusion reactor going. The remaining neutrons can be used for other purposes.

Once the tritium is bred, the remaining slower neutrons are fed into either ${ }^{232} \mathrm{Th}$ or ${ }^{238} \mathrm{U}$. We consider only the former, since the latter breeds plutonium, a material we would like to avoid as much as possible. The thorium absorbs a slow neutron to become ${ }^{233} \mathrm{Th}$, but this is unstable to a double beta decay. It has a half life of $22 \mathrm{~min}$ and then decays to ${ }^{233} \mathrm{~Pa}$, which is also unstable and decays to ${ }^{233} \mathrm{U}$ with a half life of 27 days. But ${ }^{233} \mathrm{U}$ is a perfectly good fissile material, i.e. a nuclear fuel for thermal neutron reactors, just like ${ }^{235} \mathrm{U}$ and ${ }^{239} \mathrm{Pu}$.

How much nuclear fuel is produced depends on the blanket design, and this paper does not get into that. One particular design $[74,75]$ has each fusion neutron producing $1 \mathrm{~T}$ after all losses, $0.6{ }^{233} \mathrm{U}$ 's, and since the breeding reactions are exothermal, the neutron energy is multiplied by about a factor of M. Recent studies estimate the $\mathrm{M}$ factor can vary between about 1.5 and 2. But for all of these, about $0.6{ }^{233} \mathrm{U}$ 's are produced from each fusion neutron. But each ${ }^{233} \mathrm{U}$, releases about $200 \mathrm{MeV}$ when burned, so the $14 \mathrm{MeV}$ neutron ultimately produces $120 \mathrm{MeV}$ of nuclear fuel, or the neutron energy produces about nine times as much nuclear fuel, to be burned in separate reactors away from the fusion reactor. Also it releases roughly from $21-28 \mathrm{MeV}$ in its own blanket. Furthermore the fusion alpha particle releases $3.5 \mathrm{MeV}$. 
This enormous increase in energy, about a factor of 10 increase in $\mathrm{Q}$ over the neutron power of the fusion reactor is reflective of the fact that fusion is neutron rich and energy poor, while fission is energy rich and neutron poor; a natural symbiosis.

Let us see what this means for a Large ITER sized fusion reactor or a NIF sized laser fusion reactor as discussed in the Introduction. It produces $1.5 \mathrm{GW}$ of neutron power. However this is multiplied say 1.8 in the blanket, so in the blanket $2.7 \mathrm{GW}$ is generated. To this, one adds the one quarter of the neutron energy which is the alpha particle energy, so the total fusion reactor power is about 3 GW. However in addition the blanket produces about 15 GWth of ${ }^{233} \mathrm{U}$ fuel. This is enough to fuel five $1 \mathrm{GWe}$ (3GWth) conventional light water reactors. At this point the driver power, seen in the Introduction as a show stopper, is now a perturbation, and we neglect it.

The current ITER is designed to produce only $1 / 3$ the neutron power of Large ITER, so it would produce about 5 GWth of nuclear fuel. This is more than enough to power a single LWR of equal power, but not enough to power very many. If LWR's are the reactor of choice, ITER would not fit as well into the infrastructure as Large ITER. However there are other reactors which burn deeper into the fertile material, require less fuel, and ITER might be able to fuel five of these. If this is the case, the requirements on a NIF sized laser fusion breeder would also be relaxed. Ref. [75] talks of a single fusion reactor fueling as many as 20 or so molten salt reactors of equal power. If this proves to be a viable mid century fission architecture, then an ITER (as opposed to Large ITER) sized fusion reactor, could fuel five or six of these. The midcentury nuclear architecture is unknowable. It will certainly have a large number of legacy LWR's. In any case, fusion breeding could play a vital role in fueling them.

There is one further complication, which is required for fusion breeding which is not necessarily required for pure fusion. A pure fusion reactor might be able to operate with either a solid or liquid blanket if it can withstand the fusion environment. There are advantages and drawbacks to each. If the blanket is a solid, the tritium can be produced there can be extracted every year or two by replacing the blanket.

But a solid ${ }^{233} \mathrm{U}$ breeding blanket does not appear to be viable. It not only breeds tritium, but also ${ }^{233} \mathrm{U}$ (or ${ }^{239} \mathrm{Pu}$ ). In the neutron flux, these continue to react, producing a witches brew of fission products, higher actinides, and an ever increasing heat load. There is a real safety issue here. A major disruption would be a real disaster.

The solution is to use a liquid blanket. It self anneals and as the liquid with the tritium and ${ }^{233} \mathrm{U}$ or Pa flow out of the reactor region, these could be removed chemically. The ${ }^{233} \mathrm{U}$ would then be mixed with ${ }^{238} \mathrm{U}$ to give a proliferation resistant fuel. Optimally, the liquid would have a free surface facing the plasma, but also it could flow in pipes. These pipes would bring in some of the complications of a solid blanket, but not many. They do not have to do anything, but withstand the fusion environment. To this author, a liquid blanket seems overwhelmingly advantageous for pure fusion. For breeding ${ }^{233} \mathrm{U}$, it is almost certainly a necessity.

If one has a liquid blanket, it does not seem to this author as if dissolving some $\mathrm{U}, \mathrm{Pa}$, or Th in the blanket will overly complicate the plasma facing parts, especially given that the neutron flux the blanket must acc.ept is much lower for fusion breeding than for pure fusion. Of course the chemical processing, to retrieve the $\mathrm{T},{ }^{233} \mathrm{U}$ or $\mathrm{Pa}$, done away from the plasma will be much more complicated than retrieving $\mathrm{T}$ alone.

This paper will not get into the blanket details, but a molten salt FLIBE blanket, containing lithium, beryllium and fluorine has been discussed in the literature. The lithium breeds the tritium and the beryllium multiplies the neutrons. Also uranium, protactinium and thorium are all soluble in it. The web site, (www.ralphmoir.com) has references to and links to several blanket designs for fusion breeding, including several old LLNL reports on the subject, which would be difficult to access in any other way. Also UCLA has a large program in blankets, studying many possible options (www.fusion.ucla.edu/abdou).

\section{A Roadmap for MFE Large Scale Power Production by Mid Century and Its Cost}

Here we only consider magnetic fusion, as so far, it alone has produced fusion neutrons in sufficient quantity. ITER is scheduled to have its first plasma by 2020 and to operate with DT in 2027. In parallel to the world's efforts on ITER, our proposal is that the United States builds the scientific prototype. Here one must initially make an important choice for fusion breeding; the blanket would have to be a liquid, hopefully initially, certainly in the ultimate configuration. The initial choice must be made to allow for a liquid blanket.

Since TFTR, JET, JT-60 and ITER have all already been designed, a great deal is already known about large tokamak plasmas, and the plasma part should be relatively easy to design. Designing and running the scientific prototype in a hydrogen or deuterium plasma should be relatively easy. Let us say the machine is first built for hydrogen or deuterium, but with space left for a breeding blanket. The machine would be run to research genuine steady state or high duty cycle operation and disruption free operation at conditions giving $\mathrm{Q} \sim 1$ if the plasma were DT. In running steady state, we note that the amps per watt produced is much less of a consideration for fusion breeding than it would be for pure fusion [51]. Let us say that designing the 
first phase of the machine takes 5 years, and the hydrogen phase also takes 5 years. That brings us up to 2024. In parallel with the hydrogen operation, a design of the breeding blanket is done, first for only tritium, and then for both tritium and ${ }^{233} \mathrm{U}$.

Immediately after the hydrogen phase, the scientific prototype would operate steady state in DT using the tritium it produces. While the tritium breeding is being examined, the ${ }^{233} \mathrm{U}$ blanket is designed. Let us say this phase takes 4 years, bringing us to 2028. At this point the scientific prototype is set to begin research as a breeder of both $\mathrm{T}$ and ${ }^{233} \mathrm{U}$. Hence ITER will begin investigating $\mathrm{Q} \sim 10,400 \mathrm{~s}$ pulse operation in DT plasmas at about the same time as the scientific prototype will begin operate as a true steady state or high duty cycle breeder of $\mathrm{T}$ and ${ }^{233} \mathrm{U}$ in a $\mathrm{Q} \sim 1$ plasma. Assuming this phase of operation takes 6 years, this takes us to about 2035. It is clear that ITER and the scientific prototype complement each other in many important ways.

If the results of both look promising, a simultaneous design would be made of a steady state $Q \sim 10$ fusion breeder. It would be called 'The Commercial Prototype'. Likely it would have a neutron power of $1.5 \mathrm{GW}$ as would Large ITER. However if the nuclear infrastructure by then uses a deeper burn and requires less bred fuel, a conventional ITER, producing $500 \mathrm{MW}$ of neutron power might suffice. If Large ITER is the choice, the neutron power would only need to be $1 \mathrm{MW} / \mathrm{m}^{2}$ on the wall, less than one fourth of that required for pure fusion. If ITER is the choice, the wall power would be only $1 / 2 \mathrm{MW} / \mathrm{m}^{2}$, about an order of magnitude less than required for pure fusion, and only a factor of two larger than the scientific prototype.

In any case, the design of the commercial prototype would begin around the early 2030s once it is clear that the scientific prototype and ITER are reasonably assured of success. It would come on line in about 2040. It runs as a breeder for 10 years, and then by 2050 the world is ready to start to mass produce them. Many would be operational by 2060. If 100 are operational by then, these would produce fuel for $500 \mathrm{GWe}$ LWR's plus the $100 \mathrm{GWe}$ that the fusion reactors themselves would produce.

Now let us see where the choice of pure fusion would lead on this roadmap. While fusion breeding is producing the 'commercial prototype', its own 'DEMO' if you will, pure fusion will have many enormous hurdles to get over. First, assuming Large ITER is the choice, it must double the fusion power to $3 \mathrm{GW}$. Then it must produce and control the alpha particle burn so that the input power can be recued from $150 \mathrm{MW}$ to say $50 \mathrm{MW}$ or less. If the fusion breeder runs at high duty factor rather than true steady state, the pure fusion reactor must find a way to operate at steady state. Then the pure fusion reactor must develop a blanket that can withstand at least twice the neutron flux of the fusion breeder. Then it must reduced the cost from about $\$ 25 \mathrm{~B}$ to about $\$ 2-5 \mathrm{~B}$ so that it can be economical. But reducing the cost by a factor of 5 or 10 means making it smaller. Making it smaller means higher wall loading and further violation of conservative design rules. It could well be caught between the devil and the deep blue sea.

These are enormous hurdles, which the pure fusion system may or may not be able to get over, and who knows how many decades it would take if it can get over them. In all this time, the fusion breeder is economically generating fuel for the world.

Now let us do a very rough estimate of the cost of the fuel produced. This is based to a large degree on what the cost of an ITER scale reactor would be. Unfortunately the cost of ITER has been increasing very rapidly, and not only is this discouraging, it makes an estimate difficult. The original cost of Large ITER was to be $\$ 10 \mathrm{~B}$ in capital cost and $\$ 10$ in operating cost for 10 years. Let us assume that he capital cost of the commercial prototype is $\$ 25 \mathrm{~B}$. The machine is assumed to last 30 years. Let us assume the same billion dollars per year operating cost.

Thus as a very rough estimate, let us say the capital and operating cost of the commercial prototype is \$2$2.5 \mathrm{~B}$ year $^{-1}$. It is reactor, which generates $1 \mathrm{GWe}$. Assuming it runs all year, and sells the power for ten cents per $\mathrm{kWh}$, it earns about $\$ 0.9 \mathrm{~B}$. But it also produces $5 \mathrm{GWe}$ of nuclear fuel. To recover the additional $\$ 1.1 \mathrm{~B}$, it would have to sell the nuclear fuel for about 2-3 cents per $\mathrm{kW} \mathrm{h}$. This estimate is certainly not exact, and as costs capital and operating costs of ITER become clearer, it can be revised.

But at this point, the estimated cost does not seem to be any kind of show stopper. Uranium fuel for LWR's now costs about one cent per $\mathrm{kWh}$, so fusion bred fuel might increase the electricity cost by a penny or two per $\mathrm{kWh}$. It is also important to note that Large ITER might play a role, at least as a stepping stone, even if the gain is only 3 . It would still produce the same $5 \mathrm{GWe}$ of nuclear fuel, but now all of the electric power produced by Large ITER (500 MW) plus another GWe of the nuclear fuel would be needed to generate the $500 \mathrm{MW}$ of beam or microwaves needed by Large ITER; leaving $\sim 4$ GWe of nuclear fuel for the grid. By the same calculation, it would have to sell this for about $6-8$ cents $\mathrm{kWh}^{-1}$; very expensive, but possibly still economical, especially if an improved version with a gain of 10 or more is on the horizon.

Furthermore mass production might well bring down the cost of fusion generated fuel by a considerable amount. After all, how much would a B777 cost if Boeing produced only one of them, or an aircraft carrier if General Dynamics made only one?

To summarize, there does seem to be a roadmap to large scale, economical power production via magnetic fusion 
breeding by mid century. Pure fusion can claim no such magnetic roadmap. Pure inertial fusion might, as there are no conservative design rules that we know of holding it back. However IFE still has to get over significant hurdles to get the neutron production that MFE has right now. Unquestionably, fusion breeding is a more conservative goal for IFE than is pure fusion; perhaps it is the only reasonable goal. A start on this path for IFE could be something like NRL's proposed Fusion Test Facility, but with a liquid liner and added tasks of breeding $\mathrm{T}$ and ${ }^{233} \mathrm{U}$.

\section{Thermal Nuclear Reactors}

Since conventional nuclear reactors are such an important part of a fusion breeder economy, this subsection and the next two give a very cursory, and much oversimplified treatment of nuclear power. Only the aspects of nuclear reactors that are most relevant for fusion breeding are emphasized here.

Every thermal nuclear reactor has three important components, the fissile material, ${ }^{233} \mathrm{U},{ }^{235} \mathrm{U}$ or ${ }^{239} \mathrm{Pu}$, the material which actually burns; the fertile material, ${ }^{238} \mathrm{U}$ or ${ }^{232} \mathrm{Th}$, which can produce additional fissile material, and the moderator, which slows down the neurons. In a nuclear reaction, the neutrons are typically emitted at an energy of about $2 \mathrm{MeV}$. However the fission cross section has a very strong maximum at low neutron energy, essentially room temperature, so one must slow down the neutrons. This is accomplished by having the neutrons repeatedly collide with a light nucleus, the moderator. Some of the excess neutrons are absorbed by the fertile material and become fissile material in the reactor, and this extends the fuel life. However the nuclear reaction also produces byproducts, which slow down the reaction. After some time, the reactor core must be discharged and the reactor must be refueled. The waste products consist of two basic classes of product. These are first fission fragments, intermediate $\mathrm{Z}$ elements which are highly radioactive, and generally have a half life of 30 years. The second are actinides, which build up from neutron absorption reactions in the fertile material; not only plutonium, but higher actinides as well, Californium, Americium and higher still. Current American policy is to containerize all the waste together and store it in a place like Yucca Mountain, where it would have to remain for perhaps half a million years (the half life of plutonium is 24,000 years). The French approach is to reprocess the waste, remove the plutonium and use it as fuel. However in this approach, the plutonium fuel in the ${ }^{238} \mathrm{U}$ fertile material is not completely burned and some fraction of the plutonium inserted is again a waste product.

Let us give a simple hypothetical example, just to illustrate the process in a very much over simplified way. Let us say that in each nuclear reaction, 2.2 neutrons are released. One is necessary to continue the chain reaction. Let us say that 0.7 are lost to various loss mechanisms, and 0.5 produce a fissile atom from fertile material. Since less than one fertile atom is produced per reaction, the reaction will ultimately run out of fuel and stop, even if there are no harmful bi products generated. The conversion ratio is defined as the number of fissile atoms produced per reaction, 0.5 in the example just given. A burner has a conversion ratio less than one, a breeder, greater.

The predominant reactor type in the world today is the light water reactor (LWR). It is certainly not the only option, but when all its advantages and drawbacks are weighed, it seems to be the optimal at this time, and likely in the future, as Freidberg and Kadak claim [20]. The lightest element for a moderator is, of course hydrogen, and this is why water is used. For the fertile material ${ }^{238} \mathrm{U}$ is used with an enrichment of about $4 \%$. In other words, each year about one metric ton of ${ }^{235} \mathrm{U}$, mixed with 24 metric tons of ${ }^{238} \mathrm{U}$ is inserted into the reactor. What is taken out of the reactor is about $750 \mathrm{~kg}$ of fission products, $200 \mathrm{~kg}$ of ${ }^{239} \mathrm{Pu}$ and about $40 \mathrm{~kg}$ of higher actinides [19], along with nearly the 24 metric tons of ${ }^{238} \mathrm{U}$ (now enriched at $\sim 1 \%$ ) which went along for the ride. The conversion ratio for the LWR is about 0.6. However it is important to understand that conversion ratio is not the only measure of how deep the burn is can be. The burn is also limited by neutron poisons, for instance xenon which builds up and absorbs neutrons. For the LWR, as we just noted, a good bit of the material removed when it is refueled, is unburned ${ }^{239} \mathrm{Pu}$ and ${ }^{235} \mathrm{U}$.

There are two important neutron loss mechanisms in LWR's, which are possible to eliminate with alternate reactor designs. First of all, the hydrogen can absorb a neutron to form deuterium. This loss can be eliminated by using heavy water, $\left(\mathrm{D}_{2} \mathrm{O}\right)$, as the moderator instead of light water. It is not as effective a moderator due to the double mass of the deuterium, but is does eliminate an important neutron loss mechanism. It allows the reactor to run with natural uranium $\left(0.7 \%{ }^{235} \mathrm{U}\right)$ instead of enriched uranium. As its conversion ratio is typically 0.8 , it burns deeper into the fertile material, so it might relax the requirements on any fusion reactor used to refuel it. This is the approach the Canadians have taken in their CANDU (Canada Deuterium Uranium) reactors. They are used throughout Canada, and the Canadians have had some success in selling them on the world market. The fuel, unenriched uranium is much cheaper, but the moderator, heavy water is much more expensive.

Secondly, using thorium as the fertile material rather than ${ }^{238} U$ greatly reduces the neutron absorption to form higher actinides. Not only does this also allows for much deeper burn, conversion ratios typically at least 0.8 , it also greatly reduces the actinides in the waste stream. However 
by using a uranium isotope as the fissile material and thorium as the fertile material, the raw fuel presents a great proliferation risk. The fissile uranium and fertile thorium can be separated chemically, and the uranium can be used to make bombs. Certainly the United States could never export this fuel.

At one time the US Navy was interested in ${ }^{233} \mathrm{U}$ fuel with thorium as a fertile material for use on submarines. It built a ${ }^{233} \mathrm{U}$ reactor and it was very successful [76]. Also proliferation is not that much of a concern for fuel on a submarine. However ${ }^{235} \mathrm{U}$ proved to be a better choice and the ${ }^{233} \mathrm{U}$ reactor was abandoned. While the author has not found an example in the literature of a fission reactor using ${ }^{233} \mathrm{U}$ as the fissile material and ${ }^{238} \mathrm{U}$ as the fertile material, there is no reason it could not work. Also there is no reason for anyone to have tried it up to now. However it is a strong contender for a fusion breeding infrastructure.

Another choice for a reactor using thorium as a fertile material is the molten salt thorium reactor (MSTR). There the thorium is dissolved in a molten salt, which flows through the reactor. A prototype $7 \mathrm{MW}$ reactor was build at Oak Ridge National Laboratory in the 1960s [77]. It too was successful, but again the effort was abandoned.

Regarding fertile material, Hans Bethe made an interesting suggestion in his classic 1979 Physics Today paper advocating fusion breeding (he called it the fusion hybrid) [13]. Since ${ }^{238} U$ as a fertile material gives better proliferation protection, but thorium produces a much easier waste stream to deal with and allows deeper burn, use a fertile material, which is half thorium and half ${ }^{238} \mathrm{U}$ in a light water reactor. At about $8 \%$ enrichment instead of $4 \%$, the raw fuel has nearly the same proliferation resistance, but the waste steam has only about half the actinide content.

As a fusion scientist, this author is not knowledgeable enough to comment, and also has no dog in the fight. A Large ITER sized reactor seems to be able to fuel 5 LWR's of equal power. However anything which provides deeper burn, eases the requirements of the fusion reactor.

\section{Fast Neutron Reactors}

As neutron energy increases, the fission cross sections decrease, making design of the reactor more difficult. However reactors using fast $(\sim 2 \mathrm{MeV})$ neutrons have been built, and these do have advantages. Additional nuclear reactions become possible, especially more complete actinide burn, and more prolific production of fertile material. To build on our hypothetical discussion of the last sub section, let us say that the fast neutron produces 3 neutron in a fission event instead of 2.2; 0.5 are lost somehow. One is needed to continue the chain reaction, and the other 1.5 are used to breed fissile atoms, so here the conversion ratio is 1.5 . One of these replaces the fertile atom lost in the reaction and the other 0.5 can be used to fuel other reactors. In this over simplified case, 2 fission breeders would power a single burner, as mentioned in the introduction.

However since the fission reaction cross sections are so low, this means that the coolant has to be virtually transparent to neutrons. This greatly restricts the choice of coolant. The most common coolant used is liquid sodium. While this sounds dangerous (it burns in air and explodes in water), liquid sodium is a common industrial material, and like many other dangerous industrial materials, there is a standard, time honored protocol for handling it, pumping it, etc.

The largest fast neutron breeder reactor hooked up to the grid was Super Phenix in France. From the outset it was plagued with difficulties and delays, mostly because there was little experience in dealing with the liquid sodium in the required large quantity. The French did finally get it to work, and it delivered 1.2 GWe to the grid for a few years. But it was always controversial and the Greens constantly protested it. On a change of government in 1997, Super Phenix was closed down [19]. However there is still one powerful breeder operational; this is $\mathrm{BN}-600$ in Russia. It has safely generated 600MWe for years.

The fast neutron reactor of most interest here is the Integral fast reactor (IFR) developed by Argonne National Laboratory [8, 14-18]. From the perspective of fusion breeding, the advantage of the IFR is that it can be run as a breeder or a burner, and the conversion ratio can vary from a low value to about 1.5 (that is 2 IFR's power a single LWR of equal power). Run as a burner, it can completely burn all transuranics and actinides. If the burner is perfectly efficient and simply burns and does not breed at all, a single IFR can burn the actinide bi product of about 5 LWR's. It does this with a process called pyroelectric separation (another common industrial process) which removes all transuranics and actinides from the waste stream, concentrates them and reinserts them into the reactor. Material posing proliferation risk never leave the reactor site, they are all burned there.

There seems to be little in the literature on the use of an IFR as a burner of actinide and transuranics from LWR's. The author has been told [78] that a more realistic figure is that an IFR can burn the waste of two LWR's on a continuous basis. Little seems to be in the literature to tie this figure down, and indeed the developers of the IFR did not see this as a primary motivation, so they had little reason to devote resources to this. However in a fusion breeder and LWR economy, the capability of an IFR to burn actinides is of paramount importance.

This series of articles [6-8] has constantly advocated the use of IFR's to burn transuranics and actinide wastes. Once burned the only waste would be the highly radioactive, 
intermediate $\mathrm{Z}$, fission products like say cobalt 60 . These have a half life of $\sim 30$ years, so they could be stored for 300-600 years until they are inert. This is a time human society can reasonably plan for; not the half million years of so the nation would have to store plutonium, an enormous proliferation risk, whose half life is 24,000 years. With the burning of actinide wastes by IFR's the need for geological disposal would be greatly reduced or even eliminated.

It may be that the author's long dream is about to become a reality. The British have contracted with GEHitachi to build a reactor called PRISM [79]. It is a scaled up version of the IFR, to generate $600 \mathrm{MW}, 10$ times that of the IFR. However its specific purpose is to burn Britain's plutonium stockpile. The British have about 100 tons of plutonium stored in various places. Since a $600 \mathrm{MWe}$ reactor burns less than a ton of fissile material per year, and the British claim that they will be able to 'treat' (in some unspecified way) all the plutonium in 5 years, they are clearly not thinking of 'burning' it all. However the PRISM fact sheet (Google GE Hitachi Prism Fact Sheet), as well as other information on the web site (gehitachiprism.com) do explain that a longer term goal is indeed to 'burn' all of the plutonium the British are storing, as well a to generate electricity from it. Hence clearly it is possible to refuel the PRISM and burn the plutonium on a continuing basis. If PRISM is successful, this could be a development of enormous importance.

\section{Problems with Nuclear Energy: and Their Solutions}

Opponents of nuclear power constantly say it is too expensive; it must and will be phased out as a failed attempt. There is a one word answer to this argument; France. France, for decades, has gotten $80 \%$ of its electricity from nuclear reactors. Somehow they manage to pay for it without going broke. As a result, the French emit considerably less $\mathrm{CO}_{2}$ into the atmosphere than other European countries their size [2].

Just because nuclear generated electricity is definitely and demonstrably affordable, does not mean it is the cheapest. Natural gas will likely be cheaper, at least in the United States for decades. But it is obviously unwise to put all of our eggs in one basket. Nuclear, which will almost certainly be vital by mid century, should play an important role today.

The author's 2004 and 2006 papers [6, 7] discussed other problems of nuclear energy mentioning safety, proliferation, waste and fuel supply. The 2006 paper blithely dismissed safety concerns with the following statement:

"Nuclear power has been criticized as dangerous and expensive almost since its birth. However in the past 25 years, the industry has compiled an impressive safety record, certainly much better than that of the coal industry."

Oops! Well, at least the last part is still true. The coal industry has killed many more people than the nuclear industry. But in the light of the Fukushima nuclear disaster, the safety of nuclear reactors in the event of extreme events obviously has to be reexamined. This author has neither expertise nor suggestions, but is confident this can be accomplished. However there are a few factors worth considering regarding technology, biology and psychology.

First consider the technology. In a nuclear disaster the main danger is to land, not people. The Fukushima earthquake and tsunami killed about 20,000 people. Hopefully, without tempting fate, the number killed so far by radiation, is zero. The people had time to get away and the nuclear workers there seem to be adequately protected. However a large area of land near the reactors may be contaminated. Thus after immediately getting people away and securing the reactor, the ultimate decontamination of the land is the highest priority in a nuclear disaster. Our recommendation is that the nuclear industry dedicate considerable resources to researching what is required here and preparing (hopefully on a worldwide basis) for such an eventuality. This will be needed only very, very rarely (and hopefully never), but once needed, the need will be acute.

Now consider the biology and ask just how decontaminated does the land have to be for humans to safely live and work there. Humans do live in a constant bath of radiation, coming from both the sky and earth. An important issue is just how harmful is low level radiation to humans? One answer is from the cancer rates of the Hiroshima and Nagasaki survivors. There are about 100,000 of them, and their health has been monitored for decades by both the American and Japanese governments. Obviously they had been exposed to vast quantities of radiation. Yet only about 800 cases of additional cancers have been caused by this exposure [80]. In other words, fewer than $1 \%$ of the survivors had developed a cancer which can be attributed to the radiation they received. This corresponds to about a $10 \%$ increase in the cancer rate among the survivors. But in the United States, the state to state variation of cancer rate varies from about 380-510 cancers per hundred thousand people per year, an increase of $30 \%$ from the state with the least cancer to that with the most.

While obviously nobody thinks that Hiroshima levels of radiation are acceptable, it does cause one to question just how harmful low levels are. At a level just a few times above background, the epidemiological measure of increase in cancer rate would be difficult to detect, because the natural and other man made causes are so much higher. This assumes the linear no threshold (LNT) model; that is every little bit of radiation causes some additional increase to the cancer rate, which is proportional to the radiation 
increase. However, medical personnel are more and more skeptical of LNT, since cells have repair mechanisms for damaged DNA. A study by Dr. Tubiana [81] and his team, published in the US National Institute of Health journal Radiology makes the case that below some specified level, increases in radiation have no adverse effects on humans. There is even a subculture, which believe that increases in low levels of radiation are beneficial to humans (Google Radiation hormesis), but this is obviously very speculative.

In any case, in decontamination of the land, technology most likely says that the levels cannot be brought to zero, and biology says they do not have to be. Likely it can be a few times above background and the result will be, at worst a nearly unmeasureable uptick in cancer rate, and more likely no increase at all.

But then there is psychology. It would be wonderful if there were an abundant, universally accepted, perfectly safe energy source. But we do not live in a perfect world. Any energy source has risks. Coal has killed many more people and destroyed much more land than nuclear ever will, and it may also cause destructive climate change. Yet people seem willing to accept coal over nuclear. Any time an anti-nuclear activist lights up a cigarette, she incurs a much greater cancer risk, than she does standing outside the nuclear power plant with her sign. Driving to the demonstration, he is at much greater risk in his car. Yet these risks are all acceptable.

Who can figure? certainly not the author, who is neither a psychologist nor pastoral counselor. But these attitudes are not necessarily permanent. They can change over a generation or so, especially if the Japanese, hopefully with international help, can render the damaged reactors inert, and decontaminate and repopulate the land.

Regarding the other problems, fuel supply, proliferation risk and waste disposal, we briefly summarize what we have already mentioned. Fuel supply can be increase by nearly two orders of magnitude by breeding. The proliferation risk of the raw fuel is negligible as long as a sufficient amount of ${ }^{238} \mathrm{U}$ is mixed in with the fertile ${ }^{233} \mathrm{U}$ or ${ }^{235} \mathrm{U}$. Regarding the spent fuel, it is a highly radioactive witches brew. However the ${ }^{239} \mathrm{Pu}$ can be separated out chemically and this is certainly a proliferation risk. However one of the main points of this paper is that the ${ }^{239} \mathrm{Pu}$ can be separated out and burned in fast neutron reactors such as the IFR, virtually eliminating this proliferation risk.

As to waste, it comes in two forms, the actinides and transuranics, which can be burned in say an IFR. Also there are the radioactive fission products, typically with half life 30 years of less. These are the only true wastes of a properly done nuclear infrastructure. The only option here is simply to store them for 300-600 years until they become basically inert. This is a time human society can reasonably plan for.
Sakharov and Bethe

Of all of the giants of twentieth century physics, two of the most gigantic were Andrei Sakharov and Hans Bethe. Yet both of these giants advocated fusion breeding [12, 13]. Sakharov, in his book, described it as one his most important ideas:

"An important proposal of mine (in 1951 or late 1950) was that neutrons from thermonuclear reactions be used for breeding purposes".

This is probably the earliest time anyone advocated the concept. Hans Bethe advocated it in a 1979 article in Physics Today. Among other things he suggested the idea of a fertile material being a mixture of ${ }^{238} \mathrm{U}$ (to minimize proliferation risks) and ${ }^{232} \mathrm{Th}$ (to minimize actinide production in the waste stream). Bethe also advocated fusion breeding rather than any other form of hybrid fusion, as his article emphasized the number of satellite reactors a single fusion breeder could support. Both of these giants have advocated fusion breeding, yet the fusion establishment ignored them for virtually the entire history of the fusion effort.

This author believes that Sakharov and Bethe had it right, and the fusion establishment has it wrong.

\section{The Energy Park}

In his earlier publications on the subject $[6-9,11]$, the author has proposed "The Energy Park" as a possible unit of power production for the future. It was called 'more than a dream, but much less than a careful plan', the idealization being that only thorium comes in, only electricity and/or manufactured liquid fuel goes out.

Basically The Energy Park consists of five $1 \mathrm{GWe}$ LWR's powered by a single Large ITER size $1 \mathrm{GWe}$ fusion reactor. The actinide waste is burned on site by a $1 \mathrm{GWe}$ IFR, if run as an essentially perfectly efficient burner. If instead it takes two IFR's [78] to 'burn' the actinide wastes of 4 LWR's, this is obviously a possible variation. The canonical configuration for the LWR's has a ${ }^{233} U$ fissile fuel, at about $4 \%$ concentration, in ${ }^{238} \mathrm{U}$, the fertile material. This provides maximum proliferation resistance of the raw fuel. However other configurations are also possible. If some thorium is mixed in with the fertile material, some proliferation resistance is lost, but the requirements on both the fusion breeder and the actinide burner are relaxed. The reason is that the LWR's now breed some ${ }^{233} \mathrm{U}$ themselves, and produce less actinides in the waste stream. Very likely a single IFR would then suffice to burn all the actinide bi products of the LWR's. Obviously there are many possible variations. However one common theme to all, is that there is no long time storage, nor long distance travel of any material with proliferation risk. There is no build up of material with 


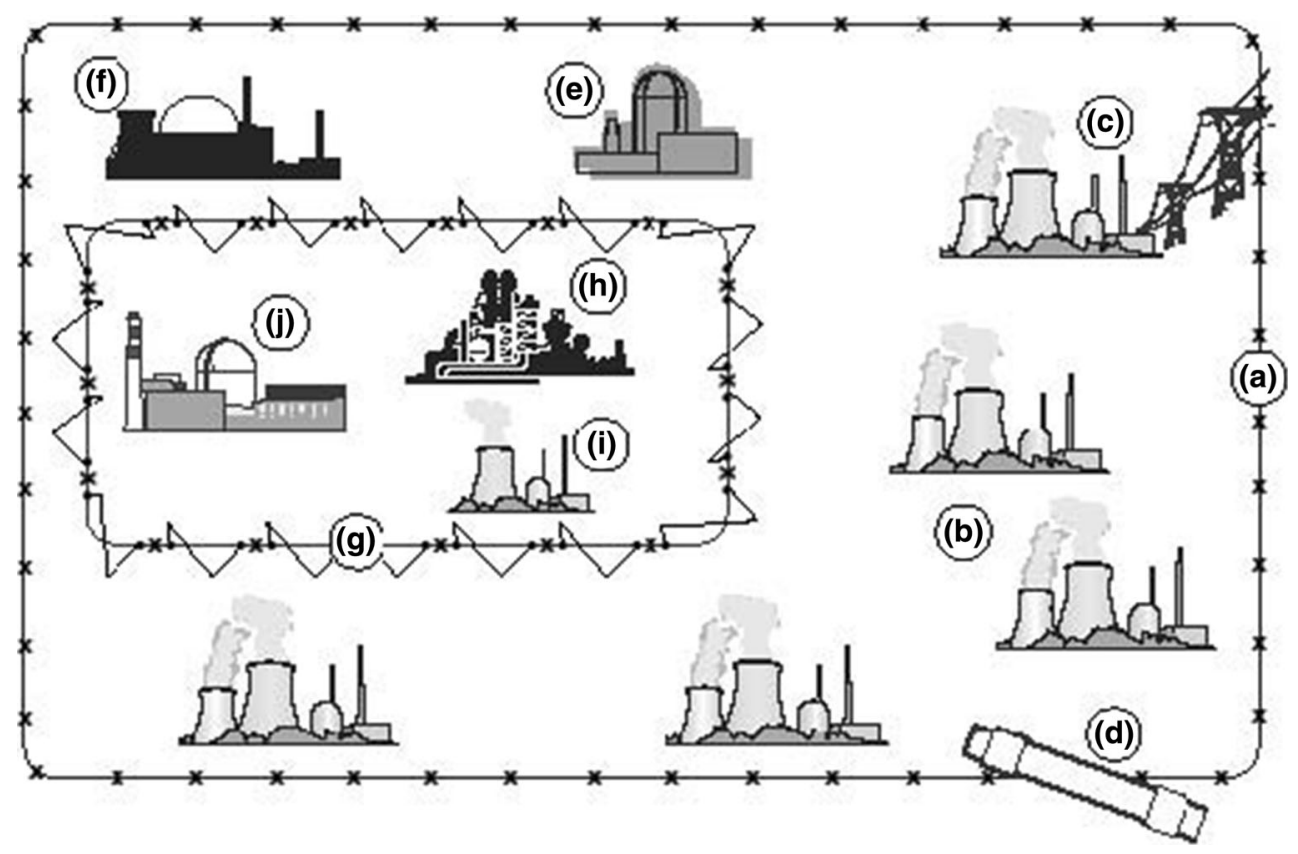

Fig. 15 The energy park, more than a dream, much less than a careful plan, ideally only thorium comes in, only electricity and liquid fuel go out. There is no long time storage, nor long distance travel of material with proliferation potential, they are destroyed in the park: $A$ Low security fence; $B$ Five $1 \mathrm{GWe}$ nuclear reactors, likely but not necessarily LWR's; $C$ electricity going out; $D$ manufactured liquid fuel pipeline; $E$ cooling pool or other storage facility where fission products are stored for the 300-500 years necessary to render them basically inert; $F$ Liquid or Gaseous fuel factory; $G$ High security fence; $H$ Separation plant. Fission products go to storage $(E)$, actinides go to; I, IFR or other fast neutron reactor where the actinides (e.g. 239Pu) are burned and; $J$ The fusion breeder proliferation risk anywhere, it is all burned on site. Only thorium comes in, only electricity and/or manufactured liquid fuel goes out.

The energy park is several square miles in area, and is surrounded by a low security fence. Inside the energy park is a high security fence, and inside this inner fence are the fusion breeder, the chemical separation plant where actinides are separated from waste stream, and the actinide burner. Thus, the industrial facilities which produce material with great proliferation risk, the ${ }^{233} \mathrm{U}$, and the actinides in the waste stream are all inside the high security fence are. The five LWR's, the storage facility for the radioactive fission products and perhaps a liquid fuel factory are all outside the high security fence, but inside the low security fence.

A schematic of the energy park is shown in Fig. 15. Assuming GE-Hitachi and the British are successful with their PRISM reactor, the only component of the energy park, which does not now exist, is the fusion breeder.

\section{Conclusions: Nirvana or Achievability?}

Pure fusion might be nirvana, but it is a long way from being achieved. It is not at all clear how tokamaks will ever get past conservative design rules, as they must for pure fusion, but certainly need not for fusion breeding. Regarding lasers, there does not seem to be any conservative design like rule restricting their parameter space, but results from the National Ignition Campaign at NIF make it clear that there are large gaps in our understanding, at least for indirect drive. However fusion breeding might be available for large scale power production by mid century. Nobody believes that is true for pure fusion.

Where will we be at mid century? The entire world, not just the currently wealthier parts of it will demand many terawatts of power. But it will almost certainly be clear then (as it is to many of us now) that solar, wind and biofuel will not be able to deliver it. Fossil fuel and mined ${ }^{235} \mathrm{U}$ may be well on their way to depletion; in addition fossil fuel may by then be causing unacceptable climate change. Fission and fusion breeding are about all that is left. If the fusion community makes a real and sustained effort to deliver economical breeders, it is unlikely that either can deliver a knockout blow to the other. Each has a significant advantage. Fission breeding has a shorter development path. However fusion breeding is a much more prolific fuel source, so it fits in well with today's nuclear infrastructure, while fission breeding does not. Freidberg and Kadak [20] claim that LWR's will be the infrastructure for a very long time. It is the choice that the world has made so far, knowing all of their advantages and 
drawbacks. Who knows where things will be at mid century, but shouldn't fusion be ready to jump in?

But to develop fusion breeders will take an enormous effort and about a $30^{\circ}$ change in course for the fusion effort. Fission breeder developers are making a real effort to be ready by mid century. Will the fusion effort then still be claiming that they will have a DEMO in 35 years, as they have been for the last 50? (I remember reading as a teenager, a Life magazine article, in the 1950s, about fusion powered rocket ships in 30 years). Fission breeding may be unable to deliver a knockout blow to fusion, but we are doing a pretty good job of delivering one to ourselves.

Let's change direction, let's propose and attempt to do something we can actually accomplish in a reasonable time. Let's make a real effort to develop fusion breeding by mid century, before our sponsors completely lose patience with us. Let's not lose the fusion project because perfect is the enemy of good enough.

Acknowledgments This work was not supported by any organization, governmental or private. I have been advocating fusion breeding for over 15 year now. As my ambition was to have this work as correct and influential as possible, I have asked six brilliant scientists, unquestioned experts in plasma physics, fusion, and nuclear energy to carefully go through all or part of it and give me their input. All agreed to do so, all did. These experts are Dr. Ralph Moir, retired from LLNL; Emeritus Professor Jeff Freidberg of MIT; Dr. Martin Lampe, retired from NRL; Professor Nat Fisch of Princeton; Professor Leon Shohet of University of Wisconsin, and Dan Meneley, a Canadian nuclear engineer who spent many years designing their CANDU reactors, as well years at ANL designing the IFR. All made very valuable suggestions; the paper after their input is in many ways quite improved from the original manuscript they saw. With several, there were quite a few back and forths. Each one agreed to be acknowledged. However this does not mean each agreed with every opinion and claim made here; how could they? This paper is meant to be nothing if not provocative and controversial. Nevertheless they all encouraged me to publish it and all agreed that I am performing an important and valuable service for the fusion community. I greatly appreciate their effort, expertise and encouragement. Finally I would like to dedicate this paper to the memory of Professor Larry Lidsky of MIT. He was the first editor of this journal and was a strong advocate for hybrid fusion. I knew him when I was a graduate student at MIT and always appreciated his insight and humor.

Open Access This article is distributed under the terms of the Creative Commons Attribution License which permits any use, distribution, and reproduction in any medium, provided the original author(s) and the source are credited.

\section{References}

1. M. Hoffert et al., Energy implications of future stabilization of atmospheric $\mathrm{CO}_{2}$ content. Nature 395, 881 (1998)

2. W. Manheimer, American physics, climate change, and energy, Forum on Physics and Society, April 2012 http://www.aps.org/ units/fps/newsletters/201204/manheimer.cfm. This study takes an intermediate view between the alarmists, who see carbon dioxide as an extreme planetary emergency, and deniers who see no problem at all in emitted $\mathrm{CO}_{2}$. Of course this is hardly the last word. This is a huge controversy. To see the alarmist side, check out the New York Times; to see the denier's side, check out the Wall Street Journal

3. MIT Technology Review, Up front. The enduring Technology of coal. May-June 2013, p. 15

4. W. Manheimer, An alternate development path for magnetic fusion. J. Fusion Energ. 20(4), 131 (2001, cc2003)

5. W. Manheimer, Back to the future, the historical, scientific, naval and environmental case for fission fusion. Fusion Technol. 36, 1 (1999)

6. W. Manheimer, The fusion hybrid as a key to sustainable development, J. Fusion Energ. 23(4) (2004, cc2005)

7. W. Manheiemr, Can fusion and fission breeding help civilization survive? J. Fusion Energ. 25, 121 (2006)

8. W. Manheimer, Hybrid fusion: The only Viable Development Path for Tokamaks? J. Fusion Energ. 28(1), 60 (2009)

9. W. Manheimer, The case for fission suppressed hybrid fusion, Forum on Physics and Society, April, 2011 http://www.aps.org/ units/fps/newsletters/201104/manheimer.cfm

10. W. Manheimer, A better option for the US fusion program, physics today, May 2012, letter to the editor, http://www.physic stoday.org/resource/1/phtoad/v65/i5/p12_s1?bypassSSO=1

11. R. Moir, W. Manheimer, Hybrid Fusion, Chapter 14 in Magnetic Fusion Technology, by Thomas Dolan (Springer, New York, 2013)

12. A. Sakharov, Memoirs (Vintage Books, New York, 1990), p. 142

13. H. Bethe, The Fusion Hybrid, Physics Today (May 1979)

14. Y. Chang, Advanced fast reactor: a next generation nuclear energy concept. Forum Phys. Soc. (2002)

15. A. Minato, 4S (Super Safe, Small and Simple LMR). Forum Phys. Soc. 35(1) (2006)

16. W. Hannum, W. Marsh, G. Stanford, Purex and Pyro are not the Same (Physics and Society, vol 32, 2004)

17. T. Beynon et al., The technology of the integral fast reactor and its associated fuel cycle. Prog. Nucl. Energy 31(1/2) (1997)

18. 1996 PBS Frontline Interview Dr. Charles Till, Co Developer of the IFR

19. R. Garwin, G. Charpak, Megawatts and Megatons (Knopf, Distributed by Random House, New York, 2001)

20. J. Freidberg, A. Kadak, Fusion-fission hybrids revisited. Nat. Phys. 5, 370 (2009)

21. D. Lightfoot et al., Nuclear fission fuel is inexhaustible, G.S. Global environmental climate change centre, McGill University, EIC Climate Change Technology Conference, 2006 IEEE, Ottawa, ON Canada, May, 2006, ISBN: 1-4244-0218-2, pp 1-8

22. D. Campbell, The physics of the international thermonuclear experimental reactor FEAT. Phys. Plasmas 8, 2041 (2001)

23. IEEE Spectrum, Projected Reactor Cost by year, 2010 inflation adjusted, September 2010

24. Feinstein: AAAS Science News, Senate spending panel votes to stop US contributions to ITER, June 25, 2013

25. M. Edwards et al., Progress toward ignition on the National Ignition Facility. Phys. Plasmas 20, 070501 (2013)

26. Daniel Clery, Fusion "breakthrough" at NIF, Uh, not really... Science on line http://news.sciencemag.org/physics/2013/10/ fusion-breakthrough-nif-uh-not-really

27. Richard M. Jones, House Defense Authorization Bill on National Ignition Facility. FYI: The AIP Bulletin of Science Policy News Number 79-June 7, 2012, http://www.aip.org/fyi/2012/079.html

28. R. Aymer, The ITER project. IEEE Trans. Plasma Sci. 25, 1187 (1997)

29. Robert Burke, Practical Near term Fusion Power, Physics Today, 63, p 59 June 2010, http://physicstoday.org/journals/doc/ PHTOAD-ft/vol_63/iss_6/59_1.shtml?bypassSSO=1 
30. HIF Fusion power company, Sacramento, CA Web site: https:// sites.google.com/site/fusionpowercorporationv30/contact-us

31. Treena Hein, Canadian firm pursues mechanical approach to fusion energy, Candian Manufacturing, May 2, $2012 \mathrm{http}: / / \mathrm{www}$. canadianmanufacturing.com/design-engineering/case-studies/ canadian-firm-pursues-mechanical-approach-to-fusion-energy62713

32. D.L. Flamm, G.K. Herb, Plasma Etching Technology-An Overview, in Plasma Etching, an Intorduction, ed. by D.M. Manos, D.L. Flamm, Academic Press, New Yok (1999)

33. H. Shirai and the JT-60 Team, Recent experimental and analytic progress in the Japan Atomic Energy Research Institute Tokamak-60 Upgrade with W-shaped divertor Configuration. Phys. Plasmas 5, 1712 (1998)

34. Y. Kusama and the JT-60 Team, Recent progress in high performance and steady-state experimentson the Japan Atomic Energy Research Institute Tokamak-60 Upgrade with W-shaped divertor. Phys. Plasmas 6, 1935 (1999)

35. S. Ide, the JT-60 Team, Latest progress in steady state plasma research on the Japan Atomic Energy Research Institute Tokamak-60 Upgrade* Phys. Plasmas 7, 1927 (2000)

36. H. Takenaga, the JT-60 Team, Improved particle control for high integrated plasma performance in Japan Atomic Energy Research Institute Tokamak-60 Upgrade Phys. Plasmas 8, 2217 (2001)

37. S. Ishida, the JT-60 Team, and the JFT-2 M Group, High-beta steady-state research and future directions on the Japan Atomic Energy Research Institute Tokamak-60 Upgrade and the Japan Atomic Energy Research Institute Fusion Torus-2 Modified. Phys. Plasmas 11, 2532 (2004)

38. A. Isayamab, the JT-60 Team, Steady-state sustainment of high- $\beta$ plasmas through stability control in Japan Atomic Energy Research Institute Tokamak-60 Upgrade. Phys. Plasmas 12, 056117 (2005)

39. A. Gibson, the JET team, Deuterium-tritium plasmas in JET, behavior and implications. Phys. Plasmas 5, 1839 (1998)

40. A. Loarte et al., Characterization of pedestal parameters and ELM energy losses iin JET and predictions for ITER. Phys. Plasmas 11, 2668 (2004)

41. F. Troyon, R. Gruber, A semi-empirical scaling law for the $\beta$ limit in Tokamaks. Physics Let. 110A, 29 (1985)

42. F. Troyon et al., Beta limit in tokamaks and computational status. Plasma Phys. Controlled Fusion 30, 1597 (1988)

43. M. Greenwald et al., A new look at density limits in tokamaks. Nucl. Fusion 28, 2199 (1988)

44. M. Greenwald, Density limits in tokamaks. Plasma Phys. Control. Fusion 44, R27 (2002)

45. L. Lidsky, End product economics and fusion research program priorities. J. Fusion Energ. 2, 269 (1982)

46. N. Fisch, J. Rax, Interaction of energetic alpha particles with intense lower hybrid waves. Phys. Rev. Let. 69, 612 (1992)

47. N. Fisch, Elementary processes underlying alpha particle channeling in tokamaks. AIP Conf. Proc. 1478, 80 (2012)

48. R. Hawryluk et al., Fusion plasma experiments on TFTR: a 20 year retrospective. Phys. Plasmas 5, 1577 (1998)

49. P. de Vries et al., Statistical analysis of disruptions in JET. Nucl. Fusion 49, 055011 (2009)

50. W. Manheimer, The scientific prototype, a proposed next step for the American MFE program. J. Fusion Energ. 32, 419 (2013)

51. T. Luce, Realizing steady state tokamaks for fusion energy. Phys. Plasmas 18, 030501 (2011)

52. J.M. Canik et al., Edge transport and turbulence reduction with lithium coated plasma facing components in the National Spherical Torus Experiment. Phys. Plasmas 18, 056118 (2011)

53. J. Brian Taylor, Relaxation of toroidal plasma and generation of reverse magnetic fields. Phys. Rev. Lett. 33, 1139-1141 (1974)
54. T. Intrator et al., A high density field reversed configuration (FRC) target a for magnetized target fusion: first internal profile measurements of a high density FRC. Phys. Plasmas 11, 2580 (2004)

55. G. Wurden et al., Magnetized target fusion: a burning FRC plasma in an imploded metal can. J. Fusion Res. SERIES 2, 238-241 (1999)

56. T. Intrator et al., A high density field reversed configuration plasma for magnetized target fusion, IEEE TPS 0200, Special issue on Plenary/invited talks, ICOPS 2003, Feb 2004

57. K. Yatsu et al., Recent developments in the GAMMA 10 experiment. Plasma Phys. Rep. 28(9), 721 (2002)

58. A. Ivanov, V. Prikhodko, Gas-dynamic trap: an overview of the concept and experimental results. Plasma Phys. Control. Fusion 55, 063001 (2013)

59. W.J. Broad, Secret Advance in Nuclear Fusion Spurs a Debate Among Scientists, New York Times, Mar 21, 1988

60. J. Nuckolls et al., Laser compression of matter to super high densities: thermonuclear (CTR) applications. Nature 239, 129 (1972)

61. R. Kirkwood et al., A review of laser-plasma interaction physics of indirect drive fusion. Plasma Physics and Con trolled Fusion 55, 103001 (2013)

62. J. Lindl et al., The physics basis for ignition using indirect-drive targets on the National Ignition Facility. Phys. Plasmas 11, 329 (2004)

63. S.W. Haan et al., Point design targets, specifications, and requirements for the 2010 ignition campaign on the National Ignition Facility. Phys. Plasmas 18, 051001 (2011)

64. T. Sangster et al., Improving cryogenic deuterium-tritium implosion performance on OMEGA. Phys. Plasmas 20, 056317 (2013)

65. D. Colombant et al., Direct drive laser target designs for sub megajoule energies. Phys. Plasmas 14, 056317 (2007)

66. S. Obenchain et al., Pathway to a lower cost high repetition rate facility. Phys. Plasmas 13, 05320 (2006)

67. S. Obenschain, J. Sethian, A. Schmitt, A laser based fusion test facility. Fusion Sci. and Tech. 56, 594 (2009)

68. R. Betti et al., Shock ignition of thermonuclear fuel with high areal density. Phys. Rev. Let. 98, 155001 (2007)

69. A. Schmitt et al., Shock ignition target designs for inertial fusion energy. Phys. Plasmas 17, 042701 (2010)

70. David Kramer, National ignition facility faces an uncertain future. Phys. Today (2013)

71. Steven Bodner, Letter to the National Academy of Sciences Committee of the Prospects for Inertial Confinement Fusion Energy Systems, and Panel of Fusion Target Physics, Dec, 2011

72. Tom Friedman, The Next Really Cool thing, New York Times op ed, March 14

73. B. Sharkov et al., Power plant design and accelerator technology for heavy ion inertial fusion energy. Nucl. Fusion 45, S291 (2005)

74. R. Moir, The fusion breeder. J. Fusion Energ. 2, 351 (1982)

75. R. Moir, Fission-suppressed fusion breeder on the thorium cycle and nonproliferationm. APS Conf. Proc. 1442, 346 (2012)

76. L. Freeman, Physics experiments and lifetime performance of the light water breeder reactor. Nucl. Sci. Eng. 102, 341 (1989)

77. H. Mac Pherson, The molten salt adventure. Nucl. Sci. Eng. 90, 374 (1985)

78. Dan Meneley, private communication, Jan 2014

79. S. Nathan, Prism Project: A proposal for the UK's plutonium problem, The Engineer, May 13, 2013 (www.theengineer.co.uk)

80. P. Voosen, Hiroshima and Nagasaki Cast Long Shadows Over Radiation Science, New York Times, April 11, 2011

81. M. Tubiana et al., Linear No-threshold relationship is inconsistent with radiation biologic and experimental data. Radiology, 251(1), 13 April 2009. http://www.ncbi.nlm.nih.gov/pmc/articles/ PMC2663584/ 